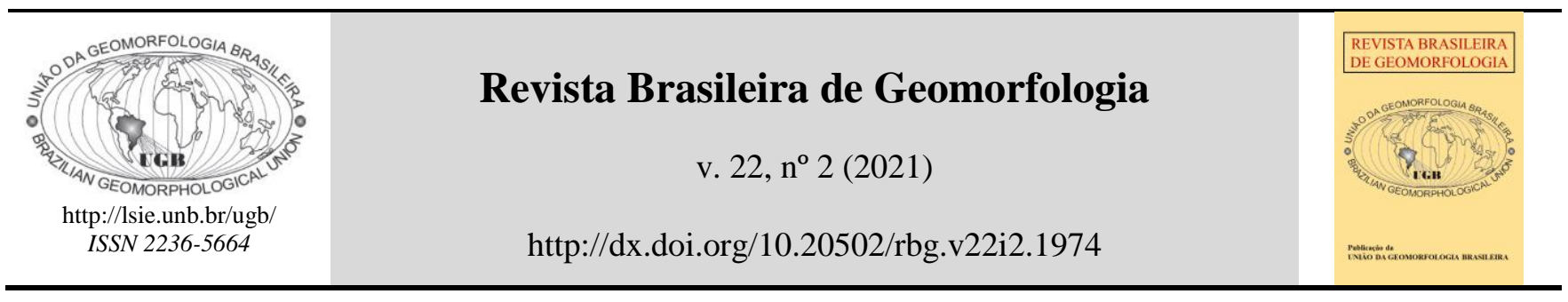

Artigo de Pesquisa

\title{
Análise morfoestrutural e aplicação do índice declividade extensão (RDE) na bacia hidrográfica do rio Ubatuba, divisa $\mathrm{CE} / \mathrm{PI}$, nordeste do Brasil
}

\author{
Morphostructural Analysis and Application of the Gradient Index (RDE) in \\ the Ubatuba drainage basin, border CE/PI states, northeast of Brazil
}

Yuri da Silva Belarmino ${ }^{1}$ e Frederico de Holanda Bastos ${ }^{2}$

1 Departamento de Geografia, Universidade Estadual do Ceará. Campus do Itaperi, Bloco G, Fortaleza, Ceará. 60740-903. Brasil ORCID: orcid.org/0000-0002-8905-0121

2 Departamento de Geografia, Universidade Estadual do Ceará. Campus do Itaperi, Bloco G, Fortaleza, Ceará. CEP: 60740-903. Brasil

ORCID: orcid.org/0000-0002-4330-7198

Recebido: 30/06/2020; Aceito: 23/12/2020; Publicado: 10/04/2021

Resumo: A bacia hidrográfica do rio Ubatuba está localizada na porção noroeste do estado do Ceará, na divisa com o Piauí, Nordeste do Brasil, e é caracterizada por aspectos morfoestruturais que condicionaram uma rede de drenagem repleta de anomalias. Tendo em vista a diversidade litológica, assim como a ocorrência de zonas de cisalhamento que cruzam o canal principal ao longo do seu perfil longitudinal, foi utilizado o índice RDE (Declividade - Extensão) para se interpretar as influências tectônicas e estruturais na drenagem em setores específicos. A presente pesquisa visa analisar a aplicação do índice RDE, além de outros índices morfométricos, na bacia do rio Ubatuba, contribuindo com a interpretação acerca da relação estrutural na organização da rede de drenagem. A pesquisa foi elaborada a partir de revisão bibliográfica acerca dos índices aplicados e do contexto morfoestrutural da área, seguida de trabalhos de campo e utilização de ferramentas de SIG. A rede de drenagem local apresenta um forte controle estrutural no alto curso associado à presença de cristas quartzíticas da Fm São Joaquim, além da influência das zonas de cisalhamento de direção NE, com ocorrências de padrões treliça e canais retilíneos. No médio e baixo curso a homogeneidade litológica dos setores do embasamento formado por rochas tenras justifica o padrão dendrítico, enquanto que nas áreas de deposição sedimentar cenozoica observam-se canais anastomosados, o que indica um baixo controle estrutural da drenagem nesses dois setores. A exceção ocorre nas áreas de exumação do granito Chaval, no baixo curso, e ao longo das zonas de cisalhamento, onde se constatam anomalias. O índice RDE identificou três principais setores de anomalias de $2^{2}$ ordem ao longo do canal principal do rio Ubatuba, sendo dois localizados no alto curso, associados à Falha de Ibuguaçu (ZC de Granja), e um localizado no médio curso, situado entre duas zonas de cisalhamento dextrais (ZC Estreito e ZC Santa Rosa). Cabe destacar que, além de possíveis relações tectônicas com anomalias fluviais, essas zonas de cisalhamento também coincidem com limites de unidades litológicas distintas, cuja ação erosiva diferencial pode condicionar inflexões nos canais.

Palavras-chave: Índice de Hack; Domínio Médio Coreaú; Semiárido Brasileiro.

Abstract: The Ubatuba drainage basin is located between the Ceará and Piauí states, in the Northeast of Brazil, and is characterized by morphostructural aspects that conditioned a drainage network full of anomalies. Associated with the lithological diversity and the occurrence of shear zones that cross the main channel along its longitudinal profile, the gradient index (RDE) was used to interpret the tectonic and structural influences on drainage in specific sectors. This research aims to 
analyze the application of the gradient index, in addition to other morphometric parameters, in the Ubatuba drainage basin, contributing to the interpretation of the structural relationship in the organization of the drainage network. The research was based on a bibliographic review about the application of the indexes presented and the morphostructural context of the area, fieldwork and the use of GIS tools. The drainage network has strong structural control in the upper course associated with the presence of quartzite ridges of São Joaquim Formation, in addition to the influence of the NE shear zones, with occurrences of trellis drainage patterns and rectilinear channels. In the medium and lower course, the lithological homogeneity of the basement sectors formed by soft rocks justifies the dendritic drainage pattern, while in the areas of cenozoic sedimentary deposition the anastomosed channels are observed, which indicates a low structural control of drainage in these two sectors. The exception occurs in the outcrop areas of Chaval granite, in the lower course, and in contact with the shear zones, where fluvial anomalies occur. The RDE index identified three main sectors of 2nd order anomalies along the main channel of the Ubatuba River, two located in the upper course, associated with the Ibuguaçu Fault (Granja SZ), and one located in the medium course, located between two dextral shear zones (Estreito SZ and Santa Rosa SZ). These anomalies may have tectonic relationships, however, it should be noted that these shear zones also coincide with the limits of different lithological units, whose differential erosive action can condition inflections in the channels.

Keywords: Hack Index ; Middle Coreaú Domai; Brazilian Semiarid Region.

\section{Introdução}

A rede de drenagem constitui importante elemento nas pesquisas geomorfológicas, cuja análise pode se direcionar para a sua função como agente modelador do relevo ou até mesmo para o controle estrutural associado ao seu desenvolvimento. As análises morfométricas em bacias hidrográficas viabilizam interpretações de correlações entre o comportamento da drenagem e componentes morfoestruturais, contribuindo para o entendimento da evolução e dinâmica da bacia (LUO; HOWARD, 2005; BEG, 2015). Os índices morfométricos podem ser divididos em três categorias principais: parâmetros de drenagem, parâmetros de área e parâmetros de relevo (PARETA; PARETA, 2011).

A morfotectônica sobre as drenagens pode ser analisada através da utilização do índice RDE (Relação Declividade-Extensão), mostrando quantitativamente mudanças abruptas e rearranjos preferenciais ao longo do perfil longitudinal dos canais de uma bacia de drenagem. Essas mudanças podem ser motivadas por movimentos verticais e horizontais, combinado com ação dos processos erosivos (RADAIDEH; MOSAR, 2019).

O índice RDE, também chamado "índice de Hack", é utilizado para caracterizar os segmentos de drenagem ao longo do perfil longitudinal. O emprego desse índice reflete o poder ou a competência do fluxo e é o produto da relação entre a inclinação e o comprimento em um determinado trecho do canal (HACK, 1973; ETCHEBEHERE et al, 2004; BARBOSA; LIMA; FURRIER, 2013). É um índice que permite analisar a potência do fluxo e a resistência ao fluxo, mostrando setores anômalos ou íngremes de riachos que estão relacionados a rochas resistentes ou frágeis (HACK, 1973; SEEBER; GORNITZ, 1983; ETCHEBEHERE et. al., 2006). Como resultado desse índice pode-se localizar as mudanças na declividade do canal fluvial e identificar deformações recentes no terreno associadas ao processo de evolução fluvial (HACK, 1973).

Nesse sentido, as drenagens, quando regidas por alterações crustais, orientam-se para direções preferenciais resultantes de elementos morfoestruturais preexistentes (BRICALLI, 2006). O que reflete no estabelecimento do seu padrão com variações de segmentos de drenagem em setores específicos, caracterizado por anomalias de padrão de drenagem (HOWARD, 1967).

Anomalias de drenagem tendem a indicar, em ambientes muito heterogêneos, mudanças bruscas e reflexos de fraturas ou segmentos topográficos. É o caso dos cotovelos de drenagem onde a angulosidade do canal forma um "L" com o segmento posterior (IBGE, 2009; BISHOP, 1995). São também anomalias as capturas fluviais, curva anômalas, drenagem colinear, trechos retilíneos de drenagem, paralelismo de drenagem, migração lateral com vale assimétrico, estrangulamento da bacia e meandros localizados (BRICALLI, 2016).

A análise do padrão de drenagem descreve a estrutura morfológica de uma rede de rios na escala da bacia hidrográfica (ZHANG; GUILBERT, 2013) e alguns padrões podem indicar condicionamentos estruturais, como treliça, retangular e paralelo dentro de um contexto de bacia hidrográfica desenvolvida sobre rochas do embasamento cristalino aplainado, o que ocorre ao longo do semiárido brasileiro.

A Província Borborema, situada no extremo NE do Brasil, apresenta uma complexa compartimentação tectônica, associada à sua evolução, sendo dividida em seu setor setentrional, em Domínios Médio Coreaú, Ceará 
Central e Rio Grande do Norte (ANGELIM et al., 2003; SANTOS; BRITO NEVES, 1984). Sobre esses domínios a prolongada ação erosiva cenozoica permitiu o desenvolvimento de uma complexa rede de drenagem, que apresenta forte relação com as deformações tectônicas neoproterozoicas do Brasiliano e com a configuração da semiaridez (PEULVAST; CLAUDINO-SALES, 2006; MAIA; BEZERRA, 2011).

O Domínio Médio Coreaú (DMC), situado no setor NW da Província Borborema, representa um compartimento estrutural fortemente deformado com sequencias de grabens e horsts divididos por zonas de cisalhamento de sentido NE, com uma complexa distribuição litológica (COSTA, et al. 1979), que condicionam redes de drenagem com expressivas anomalias.

Face ao exposto, a presente pesquisa tem como objetivo uma análise morfoestrutural a partir da aplicação do índice RDE na bacia do rio Ubatuba, situada no DMC, de modo a interpretar os fatores estruturais associados à evolução e o comportamento da rede de drenagem.

\section{Localização da área de estudo e aspectos litológicos e geomorfológicos}

A bacia de drenagem do rio Ubatuba ocupa uma área de 1076,01 $\mathrm{km}^{2}$, tendo uma rede de drenagem de $6^{\mathrm{a}}$ ordem e um relevo com altitudes que chegam a cotas próximas de $900 \mathrm{~m}$. Localiza-se no NW do estado do Ceará e extremo NE do estado do Piauí. A Figura 1 apresenta a localização da bacia do rio Ubatuba, assim como sua configuração morfológica.

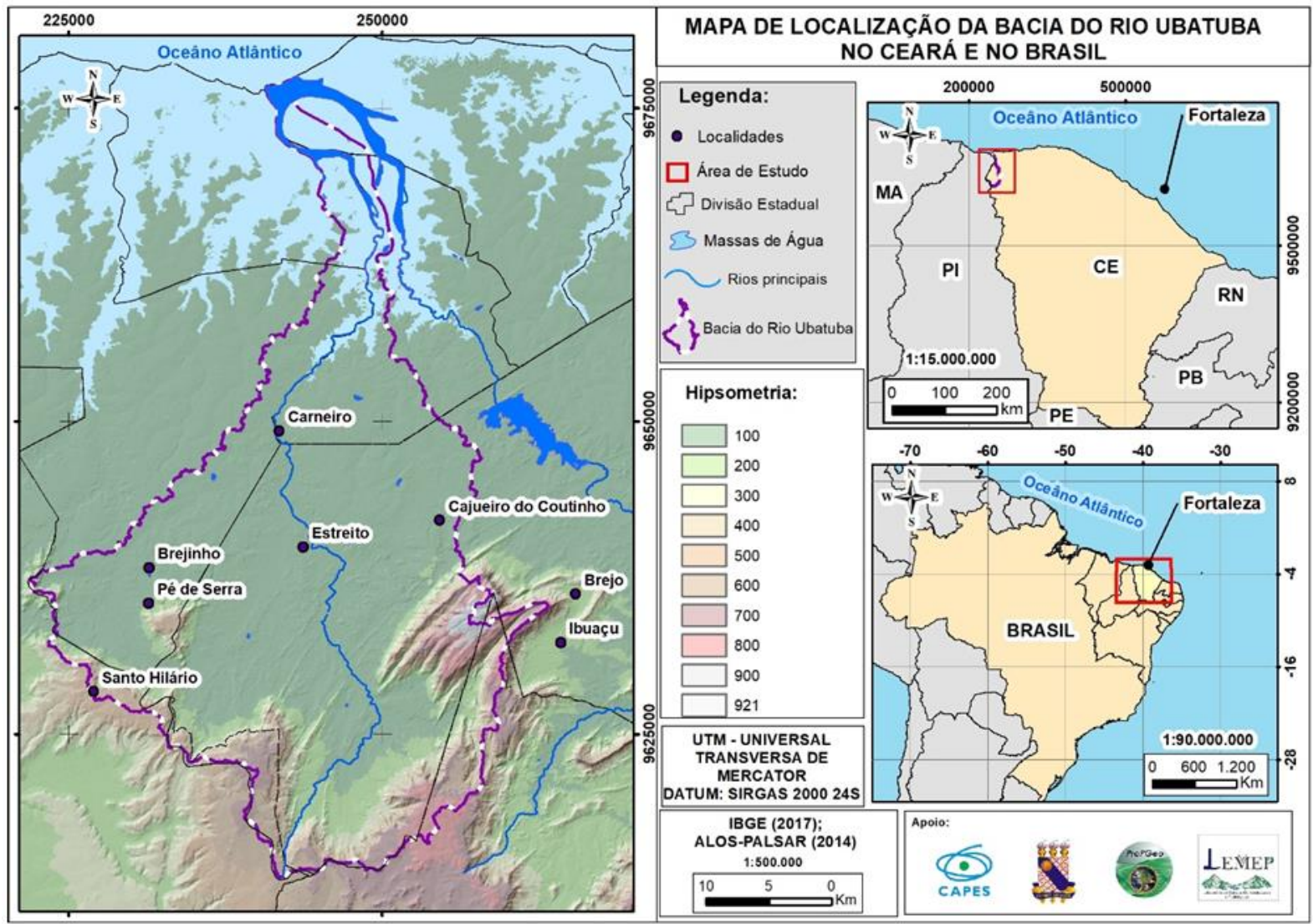

Figura 1. Localização da bacia hidrográfica do rio Ubatuba, Ceará, Brasil.

Do ponto de vista estrutural a área de estudo se situa no DMC, no limite ocidental da Província Borborema, que se trata de um setor tectonicamente deformado por zonas de cisalhamento, cuja evolução geológica permitiu o desenvolvimento de uma complexa gama de litologias (TORQUATO; NOGUEIRA NETO, 1996; SANTOS et al., 2008; SAADI; TORQUATO, 1992), preferencialmente composta por rochas paraderivadas e intrusivas. Esse domínio é descrito como uma região de dobramentos relacionada às tensões da orogênese brasiliana (540 MA) (BRITO NEVES, 1975), sendo delimitado a leste pela Zona de Cisalhamento (ZC) Sobral - Pedro II (Lineamento Transbrasiliano) e a oeste com a Província Parnaíba (ALMEIDA et al., 1997). 
A complexidade estrutural do DMC é produto do choque intraplaca que originou, no Neoproterozoico, uma cadeia de montanhas (Orogênese Brasiliana), a qual foi rebaixada pelos agentes erosivos (SANTOS; BRITO NEVES, 1984). Parte da deposição paleozoica dos sedimentos provenientes dessa cadeia montanhosa foram acomodados na sinéclise Parnaíba, cuja camada basal (Grupo Serra Grande) pode ser identificada no setor sul da bacia hidrográfica do rio Ubatuba.

O Grupo Serra Grande sustenta os setores mais elevados da área de estudo e já fazem parte de outra grande unidade estrutural regional, a Província Parnaíba. A Bacia sedimentar do Parnaíba, no contexto da área de estudo, está embutida no substrato formado por crátons sinbrasilianos e cinturões orogenéticos brasilianos bastante falhados (SILVA et al., 2003). Suas sequências possuem gênese policíclica, associada a sucessivos eventos de imersão da superfície da plataforma abaixo do nível de base regional e seu soerguimento subsequente (ABREU et al., 1988; BRITO NEVES, 1975, CACAMA, 2015). Do ponto de vista geomorfológico a feição evoluiu por meio de soerguimentos responsáveis pelo recuo da borda da bacia em cada ciclo denudacional regional, conforme as condições climáticas e tectônicas vigentes.

A bacia hidrográfica do rio Ubatuba apresenta litologias associadas às seguintes unidades: (I) Complexo Granja, (II) Suíte Intrusiva Chaval, (III) Grupo Martinópole, (IV) Grupo Jaibaras, (V) Grupo Serra Grande e os (VI) Depósitos Cenozoicos (ABREU et al., 1988) (Figura 2).

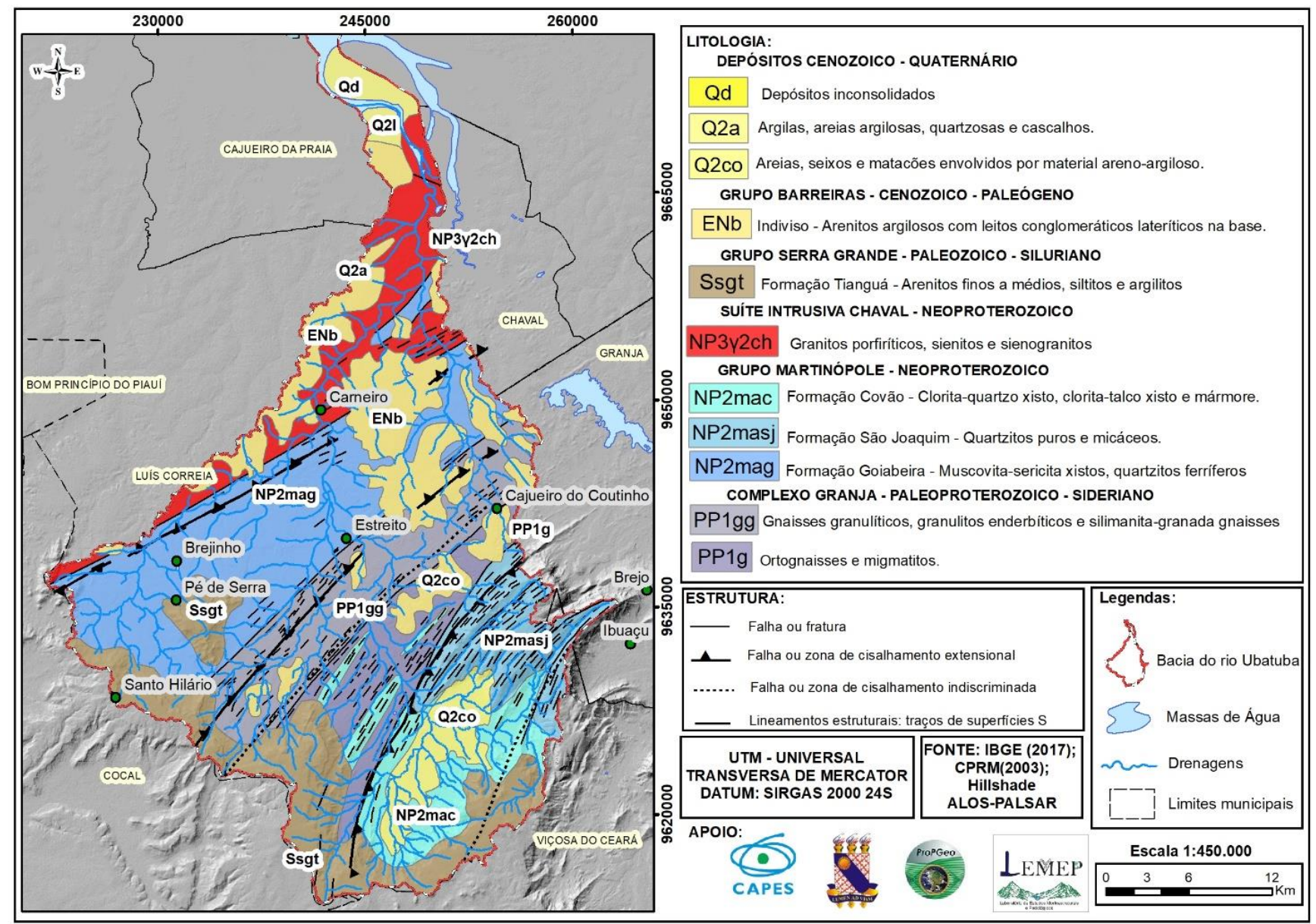

Figura 2. Geologia da bacia do rio Ubatuba.

Os compartimentos tectônicos da bacia se apresentam em uma sequência de horst e grabens. São eles o horst Granja de sentido NE-SW seccionado pelas ZC de Granja e Santa Rosa; graben Martinópole na forma de arco deprimido entre altos topográficos e caracterizado por intenso falhamento normal e direcional de sentido NE-SW; e o horst Tucunduba formado por migmatitos, quartzitos e gnaisses que exibem um estilo tectônico com destaque para os dobramentos de sentido NE-SW (COSTA et al., 1979) (Figura 3). 


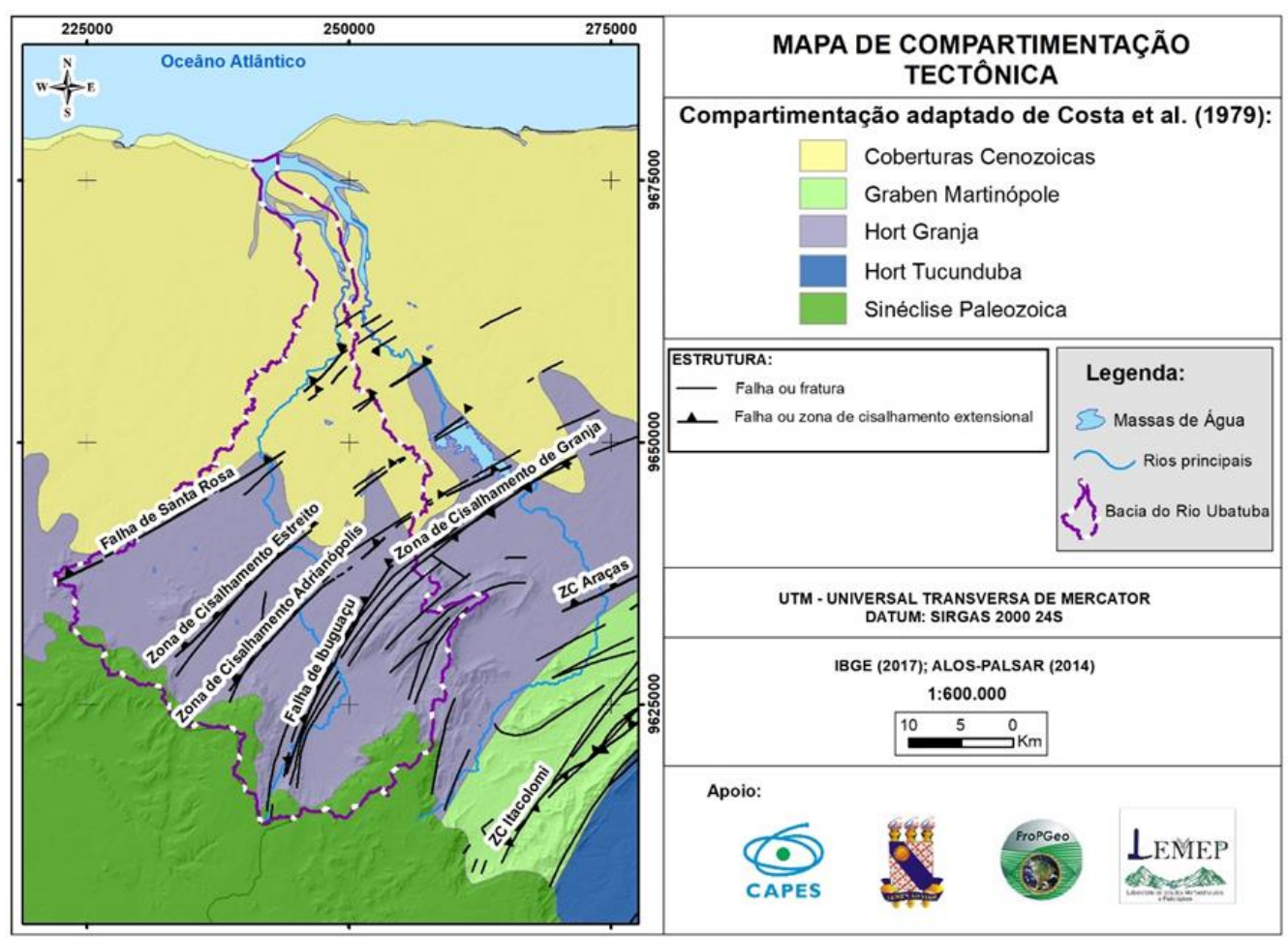

Figura 3. Mapa de Compartimentação tectônica adaptado de Costa et al. (1979).

Do ponto de vista geomorfológico a bacia hidrográfica do rio Ubatuba se apresenta como um anfiteatro erosivo que se desenvolveu a partir dos limites setentrionais do glint da Ibiapaba $( \pm 900 \mathrm{~m})$, este sustentado por arenitos do Grupo Serra Grande. O contato com a superfície erosiva rebaixada $( \pm 150 \mathrm{~m})$, desenvolvida sobre rochas do embasamento cristalino indiviso, ocorre de forma abrupta com diversos setores escarpados. Com a remoção do arenito em determinados setores, despontam cristas de quartzito que tiveram grande relevância na organização da rede de drenagem e constituem divisores de água de microbacias (Figura 4).

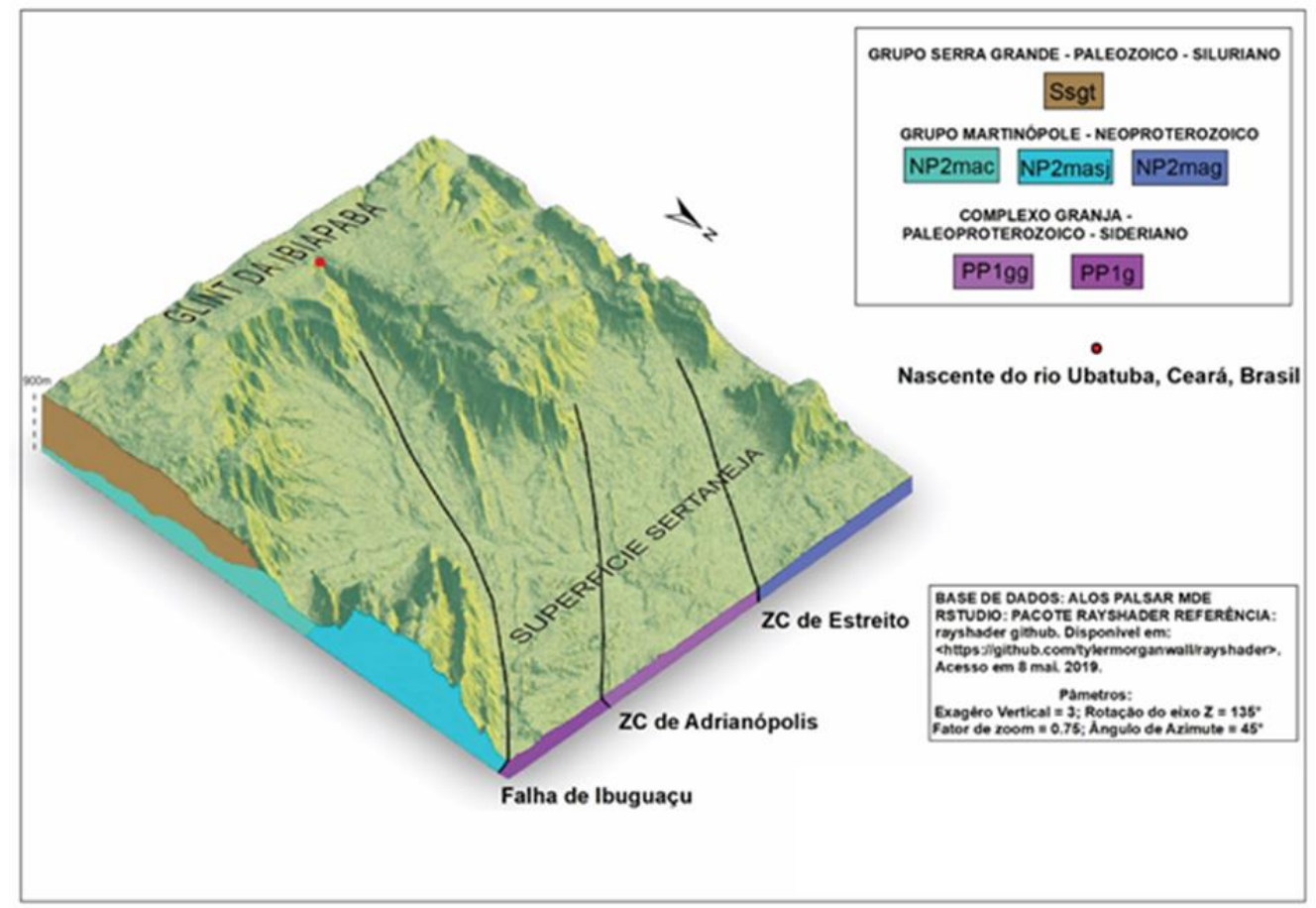

Figura 4. Bloco diagrama representativo dos aspectos morfoestruturais do alto curso da bacia do Ubatuba. (Legenda: Ssgt - Grupo Serra Grande; NP2mac - Fm Covão; NP2masj - Fm São Joaquim; NP2mag - Fm Goiabeiras; PP1gg/PP1g - Complexo Granja. 
Os arenitos do Grupo Serra Grande sustentam o glint da Ibiapaba, reflexo da expressiva resistência dessa litologia que mantém uma cornija arenítica nos setores mais elevados da bacia hidrográfica, constituindo o limite nordeste da bacia sedimentar do Parnaíba. Cabe destacar que o comportamento estrutural desse relevo justifica a sua classificação como um glint, tendo em vista se tratar de um escarpamento formado por um contato discordante entre os arenitos do Grupo Serra Grande sobrepostos ao embasamento.

O comportamento poroso da cornija arenítica favorece a infiltração no seu platô e a resistência à erosão cenozoica sob condições climáticas atuais (CLAUDINO-SALES; LIRA, 2011). O rio Ubatuba é caracterizado como um rio obsequente que drena no sentido oposto ao caimento das camadas sedimentares da bacia do Parnaíba, sendo o responsável pela erosão remontante.

O comportamento morfológico das encostas do glint se dá através de escarpamentos, associados a cornijas areníticas do Grupo Serra Grande (Fm Tianguá), seguido de um pedimento cristalino dissecado $( \pm 550 \mathrm{~m})$, situado logo abaixo (CLAUDINO-SALES; LIRA, 2011; MOURA-FÉ, 2017). Na base desse pedimento encontra-se a superfície erosiva rebaixada $( \pm 150 \mathrm{~m})$, desenvolvida sobre rochas do embasamento (Figura 5 ).

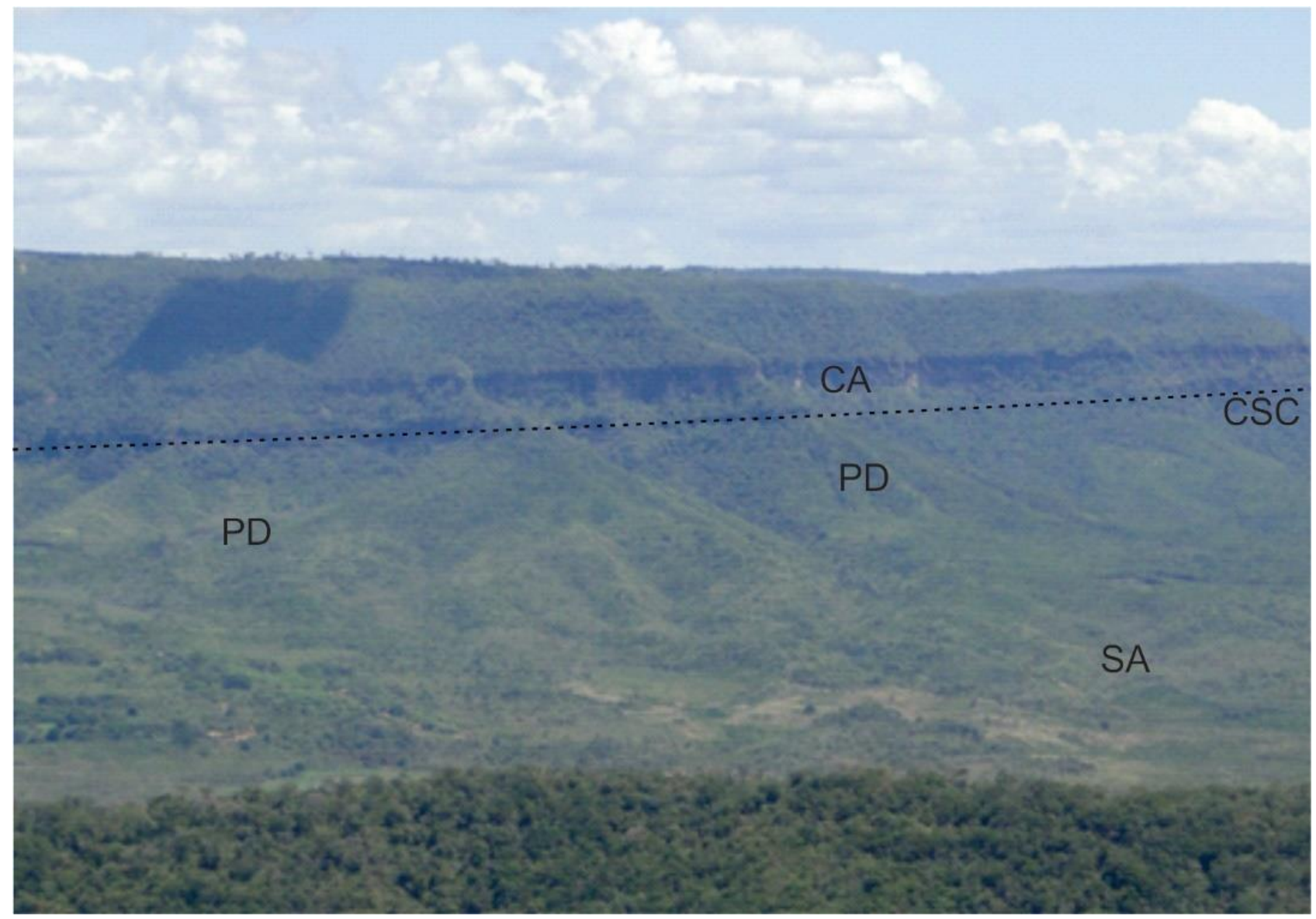

Figura 5. Glint da Ibiapaba, setor setentrional. (Legenda: CA: Cornija arenítica; CSC: Contato litológico entre rochas sedimentares e o embasamento cristalino (linha tracejada); PD: Pedimento dissecado; SA: Superfície de aplainamento).

A maior parte da bacia drena sobre superfícies erosivas rebaixadas, regionalmente conhecidas como "Depressão Sertaneja". Essas vastas superfícies são formadas por ciclos denudacionais poligênicos e possuem topografia suavemente ondulada, podendo apresentar feições residuais associadas à erosão diferencial (BIGARELLA; MOUSINHO; SILVA, 2016; MAIA; BEZERRA; CLAUDINO-SALES, 2010; SOUZA, 1988). Parte dessas superfícies desenvolveu-se sobre rochas de complexos Gnáissico-migmatíticos e outra, de menor dimensão espacial, sobre rochas sedimentares do Grupo Jaibaras. As altitudes nesse setor variam entorno de 150 a $300 \mathrm{~m}$, com declividades entre $3 \%$ a $20 \%$. 
Os relevos residuais no contexto da área de estudo, constituem sobressaltos topográficos relacionados aos granitos de Chaval e aos quartzitos da Fm São Joaquim. No batólito de Chaval, a erosão diferencial permitiu o desenvolvimento de um campo de inselbergs situado no baixo curso da bacia, já em ambientes estuarinos.

A elevada resistência dos quartzitos da Fm São Joaquim justifica o desenvolvimento de cristas. Tais litologias sofreram deformações dúcteis relacionadas a áreas de falhas de cavalgamento (SANTOS et al., 2008; ABREU et al., 1988; TORQUATO; NOGUEIRA NETO, 1996). As cristas residuais, na área de estudo, apresentam-se agrupadas, com drenagem condicionada ao formato longitudinal das vertentes desse tipo de relevo. Reúnem em seus aspectos característicos os lineamentos positivos, poucos detritos em suas vertentes e topo bastante aguçado, geralmente no mesmo sentido que os trends estruturais (NE - SW).

Desse modo, o processo de erosão diferencial rebaixou as rochas paraderivadas e expôs em sobressalto topográfico os quartzitos, que despontam a partir da vertente do glint da Ibiapaba tendo grande relevância na organização da rede de drenagem, constituindo importantes divisores de água de microbacias.

No baixo curso da bacia encontram-se os tabuleiros pré-litorâneos, que compreendem uma superfície tabular geologicamente representada por sedimentos neógenos do Grupo Barreiras. Os relevos recentes, associados com áreas de deposição quaternária, são representados pelas planícies fluviais e a planície litorânea (planície flúvio-marinha).

\section{Materiais e Métodos}

Necessitou-se para realização da presente pesquisa da realização de levantamento bibliográfico sobre teoria e aplicação do índice fator de assimetria, integral hipsométrica e o próprio índice RDE, além de dados sobre contexto estrutural e do quadro natural da área de estudo.

Os procedimentos cartográficos tiveram como base um banco de dados georreferenciados, com os quais foi possível a produção de mapeamento temático da bacia do rio Ubatuba. O banco de dados georreferenciados adotou a projeção cartográfica Universal Transversa de Mercator (UTM) e Datum - Sistema de Referência Geocêntrico para as Américas de 2000 (SIRGAS 2000).

Foram utilizados dados vetoriais e matriciais disponíveis para a área de estudo. Os dados vetoriais foram: validação da elevação com as SCN_Carta_Topografica_Vetorial-CHAVAL-SA-24-Y-C-II; SCN_Carta_Topografica_Vetorial-VIÇOSADOCEARÁ-SA-24-Y-C-V- ambas com escala de 1:100.000, caracterização geológica da Folha Granja (NOGUEIRA NETO et al., 2014) e Folha Chaval (PINÉO et al., 2018) ambas com escala de 1:100.000, e do mapa geológico do Estado do Ceará, na escala de 1:500.000 (CAVALCANTE et al., 2003). As interpretações morfoestruturais locais se deram a partir dos dados cartográficos citados na escala de 1:100.000, enquanto que o mapa geológico de 1:500.000 foi utilizado na interpretação do contexto estrutural regional.

Recorreu-se a uma imagem raster, em matriz regular quadrada numérica, com valores de elevação. Desse modo, foi utilizado o MDE de duas imagens Advanced Land Observing Satellite-1 ALOS/PALSAR disponibilizadas pela Alaska Satellite Facility (AP_26664_FBS_F7110_RT1; AP_26664_FBS_F7120_RT1) que proporcionou um mosaico de imagem da área com buffer de $4 \mathrm{~km}$ e resolução espacial de $12,5 \mathrm{~m}$. A imagem foi tratada e modificada através de procedimentos na calculadora raster para exclusão de dados nulos e negativos. Assim se obteve um MDE (Modelo Digital de Elevação) hidrologicamente corrigido para a área analisada.

Para o cálculo do índice RDE foi escolhido o rio de maior extensão e hierarquia da bacia, segmentando-o em tamanhos semelhantes, de maneira a se analisar o RDE-trecho para cada setor segmentado (BARBOSA; LIMA; FURRIER, 2013). O cálculo é baseado na diferença entre dois pontos extremos de um segmento ao longo do curso d'água representado por $\Delta \mathrm{H}$ e na projeção horizontal do referido segmento $(\Delta \mathrm{l})$. Assim $\Delta \mathrm{H} / \Delta \mathrm{l}$ corresponde ao gradiente da drenagem no trecho. Em virtude de uma análise geral (cabeceira e foz), o índice RDE-total pode ser calculado para toda a extensão de um rio ou um segmento de drenagem qualquer. O RDE total é obtido a partir da relação de toda a extensão do curso d'água e a amplitude altimétrica total (cota da foz - cota da cabeceira) e o logaritmo natural de toda a extensão (BARBOSA; LIMA; FURRIER, 2013; ETCHEBEHERE et. al., 2006; ETCHEBEHERE, et. al., 2004).

O índice RDE pode ser calculado da seguinte forma (BARBOSA; LIMA; FURRIER, 2013; ETCHEBEHERE, et. al., 2006; ETCHEBEHERE, et. al., 2004): 


$$
\begin{gathered}
R D E(\text { total })=\frac{\Delta \mathrm{H}}{\log L} \\
R D E(\text { trecho })=\left(\frac{\Delta \mathrm{H}}{\Delta \mathrm{L}}\right) \times \mathrm{L}
\end{gathered}
$$

No cálculo do RDE (total), $\Delta \mathrm{H}$ é a diferença altimétrica entre a cota localizada na cabeceira do rio e a cota localizada na foz do mesmo e log L é o logaritmo natural da extensão total do curso de água. No RDE (trecho): $\Delta H$ é a diferença altimétrica entre dois pontos selecionados no curso de água; $\Delta \mathrm{L}$ é o comprimento sinuoso do trecho analisado; e L corresponde à extensão total (em linha reta) do trecho analisado.

Os trabalhos de campo tiveram objetivo de se averiguar as características levantadas em gabinete com o uso do SIG, além da consolidação da interpretação geomorfológica em campo e aquisição de acervo fotográfico.

As etapas de manipulação, finalização e tratamento das imagens utilizadas, foram operacionalizadas por meio de software Quantum GIS 3.2.1 Bonn, disponibilizado pela Open Source Geospatial Foundation (OSGeo). Em contrapartida foi aplicada a correlação de imagem sombreada a imagem RGB no software GIMP 2.10.8 e criação de bloco diagrama com as funções presentes no SketUp 2020 e V-Ray. Como meio de representação também foi utilizado o pacote de representação do RStudio afim de criar o melhor desenho as imagens usadas na pesquisa.

\section{Resultados e Discussão}

\subsection{Lineamentos Morfoestruturais e Rede de Drenagem}

Ao se analisar o comportamento da rede de drenagem da área de estudo compreende-se que a sua evolução é condicionada pelo comportamento dos grandes sistemas estruturais e da heterogeneidade litológica. Dessa forma, o fator morfoestrutural pode ser analisado através das feições geomorfológicas lineares mapeáveis por sensoriamento remoto, cujas partes são alinhadas em uma relação retilínea que repercutem na superfície fatores de subsuperfície (O'LEARY, FRIEDMAN; POHN, 1978; BRICALLI, 2016).

A derivação do MDE para uma imagem com sombreamento (hillshade) mostrou-se eficiente na delimitação de lineamentos morfoestruturais da área de estudo, considerando-se altos e baixos topográficos, ou seja, lineamentos positivos e negativos. Na vetorização dos lineamentos positivos avaliou-se os segmentos retilíneos escarpados, cristas alinhadas de cumes, limites de áreas elevadas e linhas de afloramentos (CHIANG, 1984). Para os lineamentos negativos considerou-se os segmentos de vales retilíneos, onde a drenagem pode ser expressa por depressões alongadas, linhas da base da escarpa e linhas de contorno de formações (CHIANG, 1984; BRICALLI, 2016). Foram analisados os azimutes e os comprimentos em quilômetros, com representação em digramas de rosetas.

O condicionamento estrutural da Província Borborema está relacionado aos grandes eventos tectônicos ocorridos ao longo de sua evolução, com destaque para a Orogênese Brasiliana (Neoproterozóico) e suas reativações juro-cretáceas por tectônica rúptil (BRITO NEVES, 1975; VAUCHEZ et al., 1995; LIMA, 2008).

Existe uma forte relação entre as deformações estruturais da Província Borborema, de sentido preferencial NE e E, com a organização da rede drenagem, sobretudo em escala regional (MAIA; BEZERRA, 2011). Além dos grandes eventos tectônicos mencionados, existem diversos elementos morfológicos e hidrográficos que refletem a importância da neotectônica no contexto regional analisado (SAADI; TORQUATO, 1992).

A área de estudo apresenta importantes deformações estruturais de sentido NE (Falha de Santa Rosa, ZC de Estreito, ZC Adrianópolis, Falha de Ibuguaçu e ZC de Granja) associadas ao Lineamento Transbrasiliano e delimitam terrenos estruturais (SANTOS et al., 2008). Tais deformações foram responsáveis pela organização tectônica local e possuem estreita relação com a variedade litológica e seus respectivos aspectos deformacionais, que constituem importantes elementos na organização da drenagem.

A maior densidade de lineamentos da bacia do Ubatuba situa-se no seu alto curso, associado ao setor de cristas quartzíticas coincidindo com o adensamento de deformação estruturais entre as ZC de Itacolomi e de Adrianópolis (Figura 6). Percebe-se que o setor de maior densidade de lineamento é bastante similar ao setor de maior densidade de canais de drenagem, conforme pode ser visto na Figura 13, a ser apresentada posteriormente. 


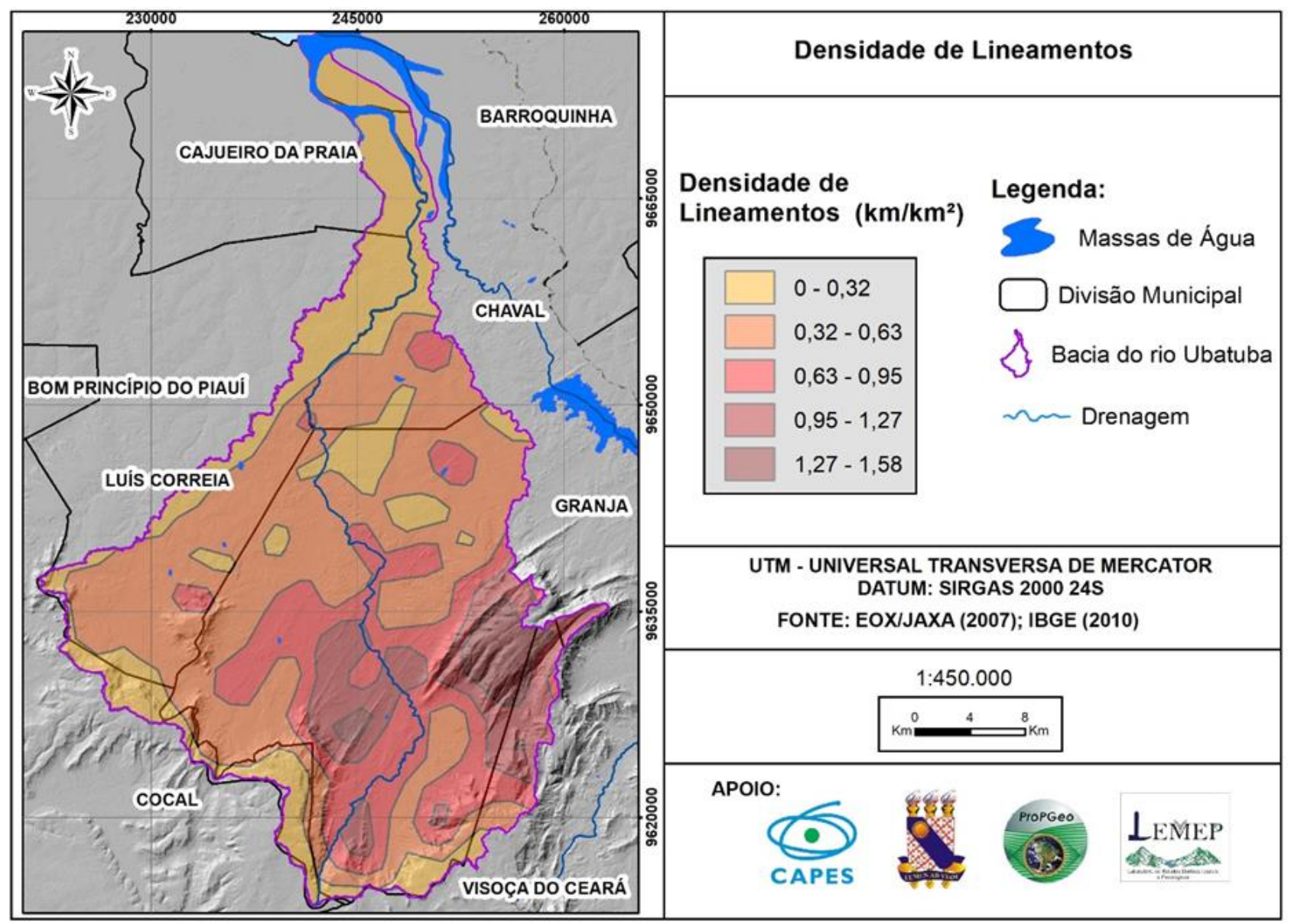

Figura 6. Densidade de Lineamentos da Bacia do rio Ubatuba, Ceará, Brasil.

Os lineamentos positivos presentes na bacia do rio Ubatuba são preferencialmente localizados no seu setor SE, com relevos dissecados. Estes têm direção preferencial NE com angulação média de 30,5ํㅜ (Figura 7). Contudo, cabe destacar que existe uma baixa concentração das formas lineares na desembocadura do rio, que se trata de um setor predominantemente deposicional.

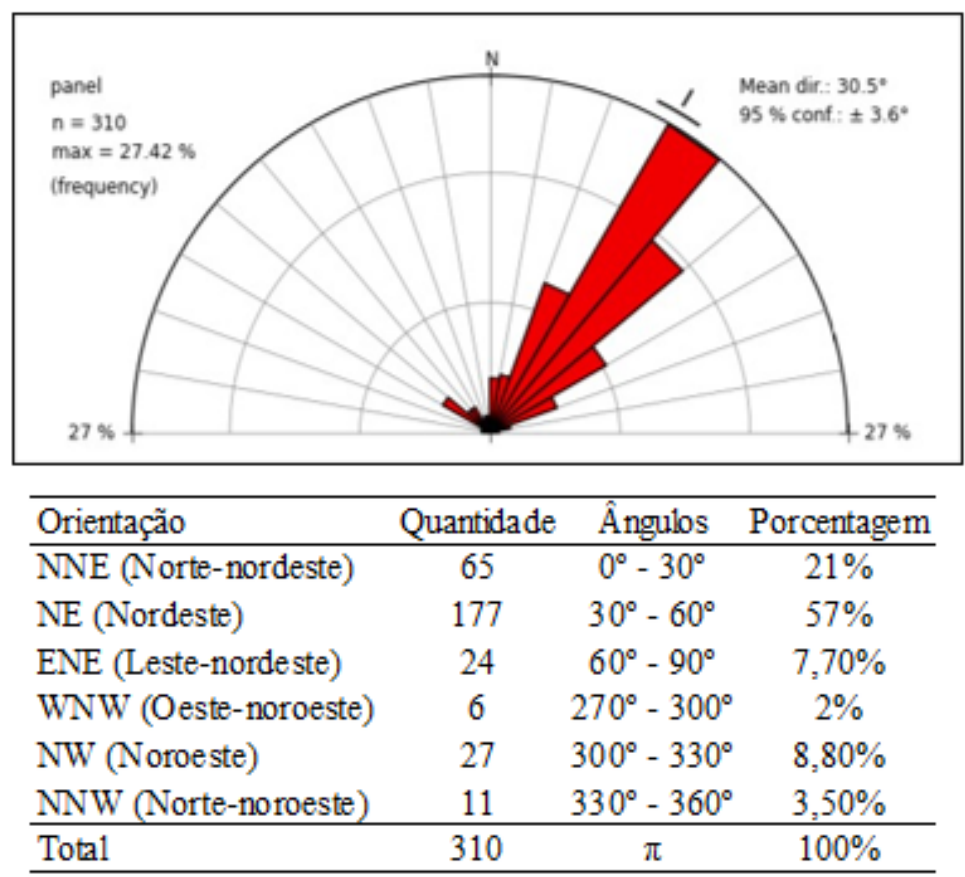

Figura 7. Diagrama de rosetas da direção preferencial e frequência de Lineamentos Positivos. 
Os lineamentos negativos são expressos, em sua maioria, na orientação NE-SW, correspondendo 30,8\% das feições, com ângulo médio de 15,7º (Figura 8). Para esse estudo a maioria dos lineamentos usados representa fundos de vales retilíneos que refletem, em grande parte, zonas de fraqueza estrutural nas litologias com mesmo sentido preferencial.

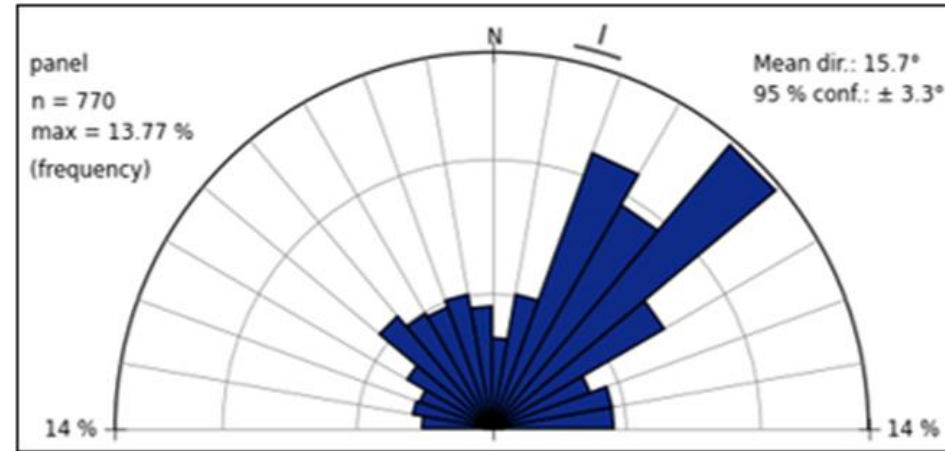

\begin{tabular}{lccc}
\hline Orientação & Quantidade & Ângulos & Porcentagem \\
\hline NNE (Norte-nordeste) & 149 & $0^{\circ}-30^{\circ}$ & $19,30 \%$ \\
NE (Nordeste) & 237 & $30^{\circ}-60^{\circ}$ & $30,80 \%$ \\
ENE (Leste-nordeste) & 91 & $60^{\circ}-90^{\circ}$ & $11,80 \%$ \\
WNW (Oeste-noroeste) & 74 & $270^{\circ}-300^{\circ}$ & $9,60 \%$ \\
NW (Noroeste) & 108 & $300^{\circ}-330^{\circ}$ & $14 \%$ \\
NNW (Norte-noroeste) & 111 & $330^{\circ}-360^{\circ}$ & $14,40 \%$ \\
\hline Total & 770 & $\pi$ & $100 \%$ \\
\hline
\end{tabular}

Figura 8. Diagrama de rosetas da direção preferencial e frequência de Lineamentos Negativos.

Quando se compara os lineamentos negativos com a rede de drenagem, pode-se perceber que parte dos canais drena no sentido NE, porém, com baixa representatividade (19,60\%) (Figura 9). Isto aponta que nem todas as drenagens são condicionadas por fatores estruturais, tendo em vista que também ocorrem canais condicionados simplesmente pela declividade, como no caso dos canais de $1^{\text {a }}$ ordem que drenam no sentido perpendicular às cristas, assim como o canal de $6^{\underline{a}}$ ordem (canal principal) que drena no sentido $\mathrm{N}$.

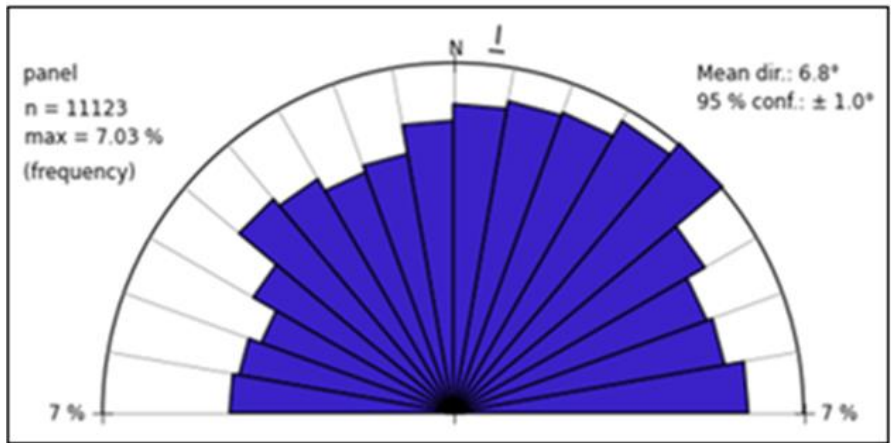

\begin{tabular}{lccr}
\hline \multicolumn{1}{c}{ Orientação } & Quantidade & Angulos & Porcentagem \\
\hline NNE (Norte-nordeste) & 2102 & $0^{\circ}-30^{\circ}$ & $18,90 \%$ \\
NE (Nordeste) & 2178 & $30^{\circ}-60^{\circ}$ & $19,60 \%$ \\
ENE (Leste-nordeste) & 1693 & $60^{\circ}-90^{\circ}$ & $15,20 \%$ \\
WNW (Oeste-noroeste) & 1610 & $270^{\circ}-300^{\circ}$ & $14,60 \%$ \\
NW (Noroeste) & 1735 & $300^{\circ}-330^{\circ}$ & $15,60 \%$ \\
NNW (Norte-noroeste) & 1805 & $330^{\circ}-360^{\circ}$ & $16,20 \%$ \\
\hline Total & 11123 & $\pi$ & $100 \%$ \\
\hline
\end{tabular}

Figura 9. Diagrama de rosetas da direção preferencial e frequência da rede de drenagem da bacia do rio Ubatuba. 
Analisou-se também os dados por cada ordem de canais na bacia de estudo, com os quais se pode ter uma visão do condicionamento mais representativo (Figuras 10 e 11). As drenagens de $1^{\underline{a}}$ ordem possuem direcionamento bastante heterogêneo, indicando ausência de forte controle estrutural. As drenagens de $2^{a}$ ordem apresentaram sentido preferencial para NE, enquanto que os canais de $3^{\underline{a}}$ ordem seguem, de forma, dispersa para NE e $\mathrm{N}$ e os canais de $4^{\underline{a}}$ ordem obtiveram direcionamento para NE com porcentagem de $19,6 \%$. As drenagens de $5^{\mathrm{a}}$ e $6^{\underline{a}}$ ordem não foram analisadas já que obedecem ao sentido N-S, seguindo para a foz.

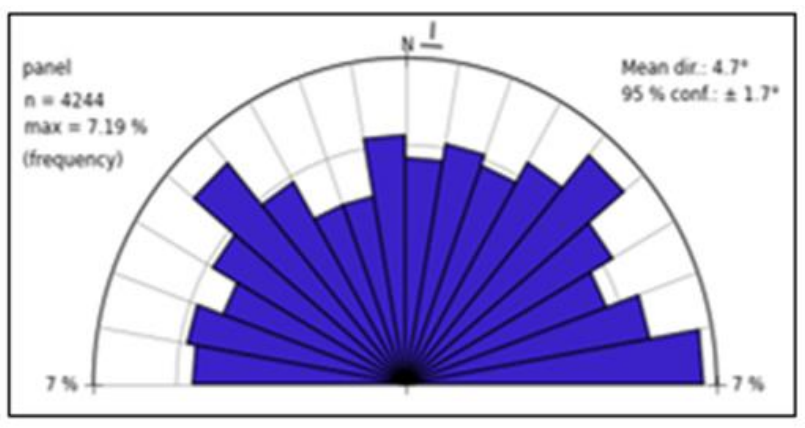

\begin{tabular}{lcr}
\hline Orientação & Ângulos & Porcentagem \\
\hline NNE & $0^{\circ}-30^{\circ}$ & $16,20 \%$ \\
NE & $30^{\circ}-60^{\circ}$ & $18,50 \%$ \\
ENE & $60^{\circ}-90^{\circ}$ & $15,60 \%$ \\
WNW & $270^{\circ}-300^{\circ}$ & $17,80 \%$ \\
NW & $300^{\circ}-330^{\circ}$ & $17,40 \%$ \\
NNW & $330^{\circ}-360^{\circ}$ & $14,50 \%$ \\
\hline Total & $\pi$ & $100 \%$ \\
\hline
\end{tabular}

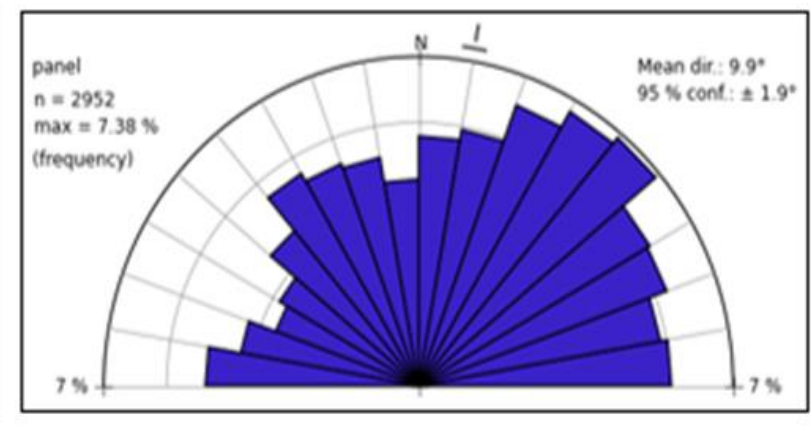

\begin{tabular}{ccc}
\hline Orientação & Ângulos & Porcentagem \\
\hline NNE & $0^{\circ}-30^{\circ}$ & $18,40 \%$ \\
NE & $30^{\circ}-60^{\circ}$ & $21 \%$ \\
ENE & $60^{\circ}-90^{\circ}$ & $17 \%$ \\
WNW & $270^{\circ}-300^{\circ}$ & $14 \%$ \\
NW & $300^{\circ}-330^{\circ}$ & $14 \%$ \\
NNW & $330^{\circ}-360^{\circ}$ & $15,40 \%$ \\
\hline Total & $\pi$ & $100 \%$ \\
\hline
\end{tabular}

Figura 10. Diagrama de rosetas da direção preferencial e frequência da rede de drenagem de $1^{\text {a }}$ (esquerda) e $2^{\mathrm{a}}$ ordem (direita) bacia do rio Ubatuba.

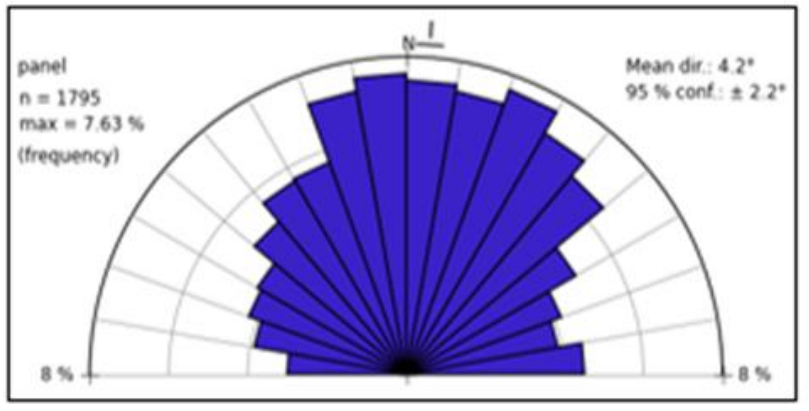

\begin{tabular}{ccc}
\hline Orientação & Angulos & Porcentagem \\
\hline NNE & $0^{\circ}-30^{\circ}$ & $22,30 \%$ \\
NE & $30^{\circ}-60^{\circ}$ & $19 \%$ \\
ENE & $60^{\circ}-90^{\circ}$ & $12 \%$ \\
WNW & $270^{\circ}-300^{\circ}$ & $12 \%$ \\
NW & $300^{\circ}-330^{\circ}$ & $15 \%$ \\
NNW & $330^{\circ}-360^{\circ}$ & $20,50 \%$ \\
\hline Total & $\pi$ & $100 \%$ \\
\hline
\end{tabular}

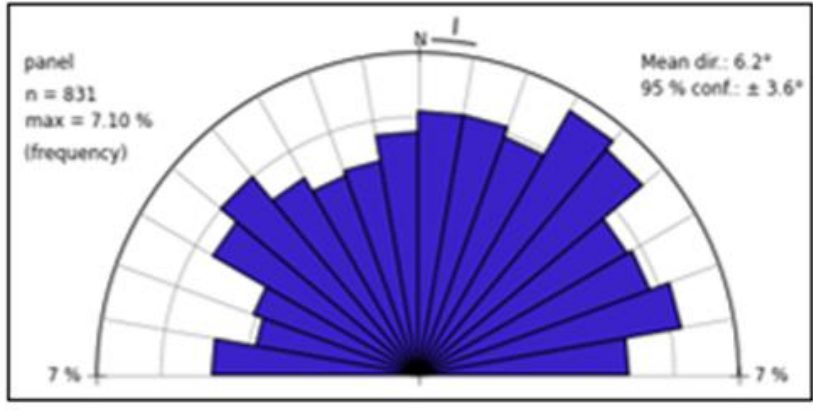

\begin{tabular}{ccc}
\hline Orientação & Angulos & Porcentagem \\
\hline NNE & $0^{\circ}-30^{\circ}$ & $18,20 \%$ \\
NE & $30^{\circ}-60^{\circ}$ & $19,60 \%$ \\
ENE & $60^{\circ}-90^{\circ}$ & $16 \%$ \\
WNW & $270^{\circ}-300^{\circ}$ & $13,70 \%$ \\
NW & $300^{\circ}-330^{\circ}$ & $16,80 \%$ \\
NNW & $330^{\circ}-360^{\circ}$ & $15,60 \%$ \\
\hline Total & $\pi$ & $100 \%$ \\
\hline
\end{tabular}

Figura 11. Diagrama de rosetas da direção preferencial e frequência da rede de drenagem de $3^{\underline{a}}$ (esquerda) e $4^{\text {a }}$ ordem (direita) bacia do rio Ubatuba. 
As drenagens de $2^{\underline{a}}$ ordem têm a maior proporção de canais influenciados pelos fatores estruturais da área de estudo, salientado a presença de rios de maior comprimento, com vales confinados. As drenagens de $3^{\mathrm{a}}$ ordem interceptam em ângulos diferentes os planos de deformações, sem grande influência direta das deformações estruturais.

Os canais apresentam trechos retilíneos, geralmente, quando existe interferência do controle litológico e também estrutural (HOWARD, 1967). Logo, a drenagem quando exposta a estímulos advindos das alterações crustais recentes, mesmo em pequenas escalas e magnitude, passa por acomodações na sua organização principalmente em gradientes altimétricos elevados (SCHUMM, 1993; CHRISTOFOLETTI, 1980).

Existe uma concentração de trechos de drenagem retilínea associada às cristas residuais (setor sul) e também na área de exposição do granito Chaval (setor norte), este último associado à orientação de falhas.

A distribuição espacial dos padrões de drenagens na bacia do rio Ubatuba está diretamente associada aos aspectos morfoestruturais locais, tendo sido identificados os seguintes padrões: Dendrítico, Subdendrítico, Treliça e Anastomosado (Figura 12).

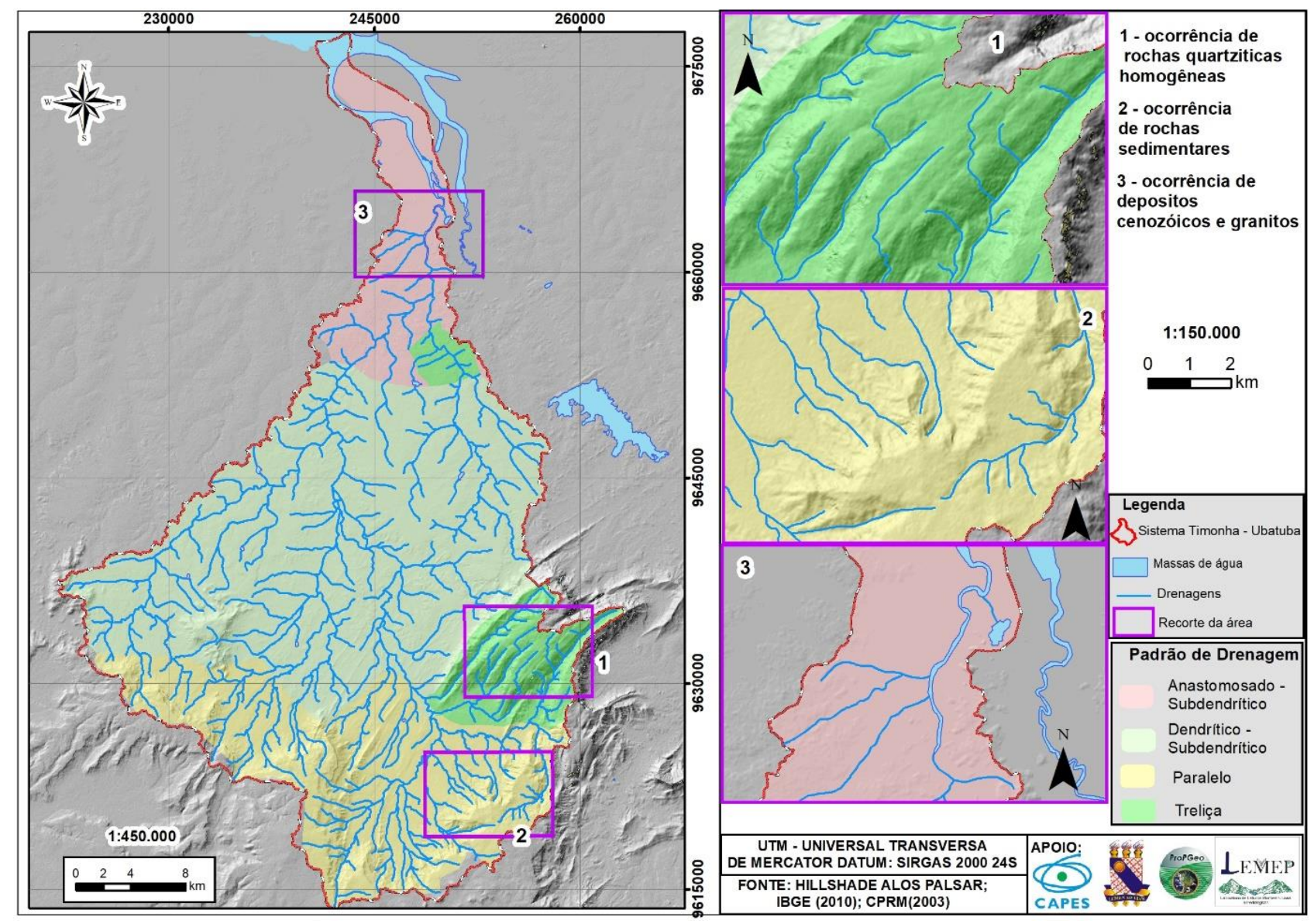

Figura 12. Padrão de drenagem da bacia do rio Ubatuba.

O padrão dendrítico foi identificado predominantemente na superfície de erosão rebaixada, onde não ocorre interferência direta da estrutura rochosa no desenvolvimento dos fluxos (CHRISTOFOLETTI, 1980; HORTON, 1945; HOWARD, 1967). Este padrão é o mais comum encontrado na natureza, principalmente onde a litologia é diversa.

O padrão subdendrítico é uma derivação do dendrítico, se diferenciando pela falta de perfeição, geralmente associada a controles regionais, estruturais ou topográficos (HORWARD, 1967). Na área de estudo esse padrão está relacionado à distinção do material litológico cristalino e com repercussões estruturais da ZC de Adrianópoles, Granja e Santa Rosa.

O padrão treliça refere-se ao padrão com ângulos retos e semi-ramificação dos canais adjacentes. Desse modo, está relacionado ao condicionamento estrutural da litologia, produzindo drenagem encaixada nos trends direcionais estruturais (HOWARD, 1967). Na área de estudo o padrão treliça está associado aos quartzitos da Fm 
São Joaquim e do granito Chaval pela influência da ZC de Santa Rosa. No caso do granito, devido ao baixo gradiente altimétrico a drenagem não tem competência para escavar a rocha exposta, definindo assim o seu traçado sobre as descontinuidades estruturais.

O padrão anastomosado compreende os fluxos com os quais o rio produz segmentos ondulados, indicando meandros e alta sinuosidade, podendo ocorrer em planícies influenciadas pelas marés (HOWARD, 1967), que é o caso da área em questão, cuja ocorrência se dá na planície flúvio-marinha do rio Ubatuba.

\section{2. Índice de Assimetria da bacia (Af)}

Pela extensão do canal principal e análise do formato da bacia, aplicou-se o índice de assimetria (Af) com o objetivo de avaliar a existência de inclinações tectônicas. O índice Af é capaz de sugerir a existência de basculamentos tectônicos em escala de bacia hidrográfica, sendo aplicado em áreas relativamente extensas e densamente falhadas (ANDRADES FILHO; ROSSETTI, 2012). A caracterização do índice Fator Assimétrico (Af) foi baseada na escala gradual proposta por Rubin (2002).

De acordo com os dados obtidos, ocorre na bacia do rio Ubatuba, para o índice Af, pouco basculamento para a esquerda $(48,256057)$. Desse modo, por se encontrar em uma área bastante falhada, o lado esquerdo do rio Ubatuba pode ter sofrido processos atuais e subatuais de basculamento, fazendo com que a drenagem principal tenha se voltado para esse sentido por influência das ZC de Adrianópolis e Estreito e Santa Rosa.

O discreto desenvolvimento da bacia para a esquerda também pode estar associado com o predomínio de litologias mais tenras nesse setor, justificando uma menor resistência litológica na evolução da bacia.

\subsection{Integral Hipsométrica (Hi)}

No tocante ao estágio de evolução da bacia e visando uma análise ao longo do perfil do rio Ubatuba, usou-se a integral hipsométrica $(\mathrm{Hi})$ como meio de análise da drenagem. Esta variável não está diretamente ligada à atividade tectônica e estabelece, em geral, qual estágio de evolução se encontra a drenagem (ANDRADES FILHO, 2010). Quando Hi > 0,5; entre 0,4 e 0,5; e Hi < 0,4 geram curvas hipsométricas convexas, côncavo-convexas ou retilíneas, e côncavas respectivamente.

Nos cálculos empregados à bacia do rio Ubatuba apresentou-se o valor de Hi de 0,49944629 ou em porcentagem de 49,94\%, que tem característica de formato côncavo-convexa. De acordo com Strahler (1952), os dados obtidos enquadram a bacia em um estágio de maturidade de relevo, com rochas de idades bastante antigas e processos complexos em sua formação. O processo denudacional da superfície sertaneja justifica interflúvios inexpressivos e vales com baixa incisão. O setor com maior rugosidade topográfica localiza-se nas cotas superiores a $300 \mathrm{~m}$, já no alto curso.

\subsection{Densidade de Drenagem}

O comprimento médio de rios de uma bacia hidrográfica por unidade de área é definido como densidade de drenagem (HORTON, 1945), que se trata de um índice diretamente associado ao comportamento da infiltração e a resistência do terreno à erosão fluvial (DINGMAN, 1978).

As drenagens para a área de estudo foram geradas de maneira automática através de SIG e refinadas em ambiente Google Earth PRO para confeccionar uma rede de drenagem mais consistente. Logo depois, este foi comparado com as informaç̃es disponíveis das cartas topográficas do Exército Brasileiro para fins de validação.

Analisando a Figura 13, pode-se perceber a irregularidade na dispersão do índice ao longo da bacia do Ubatuba. Compreende-se que a densidade de drenagem se apresenta como uma variável tanto qualitativa como quantitativa da rede de drenagem, produto do regime de chuvas e da morfologia do terreno da bacia hidrográfica (BAHRAMI, 2013).

A bacia do rio Ubatuba apresenta canais concentrados em valores de densidade média a alta, principalmente nos terrenos de litologias antigas e nas transições entre os relevos sedimentares e a superfície de erosão rebaixada. No cálculo proposto por Horton (1945) e Strahler (1952), o valor apresentado para área da bacia foi de 0,91 $\mathrm{km} / \mathrm{km}^{2}$.

As densidades médias se concentram preferencialmente no embasamento cristalino rebaixado. Densidades baixas a muito baixas predominam nos terrenos de litologias sedimentares, como é o caso das rochas da bacia 
sedimentar do Parnaíba e dos tabuleiros, onde a porosidade e a topografia tabuliforme limitam o desenvolvimento de canais.

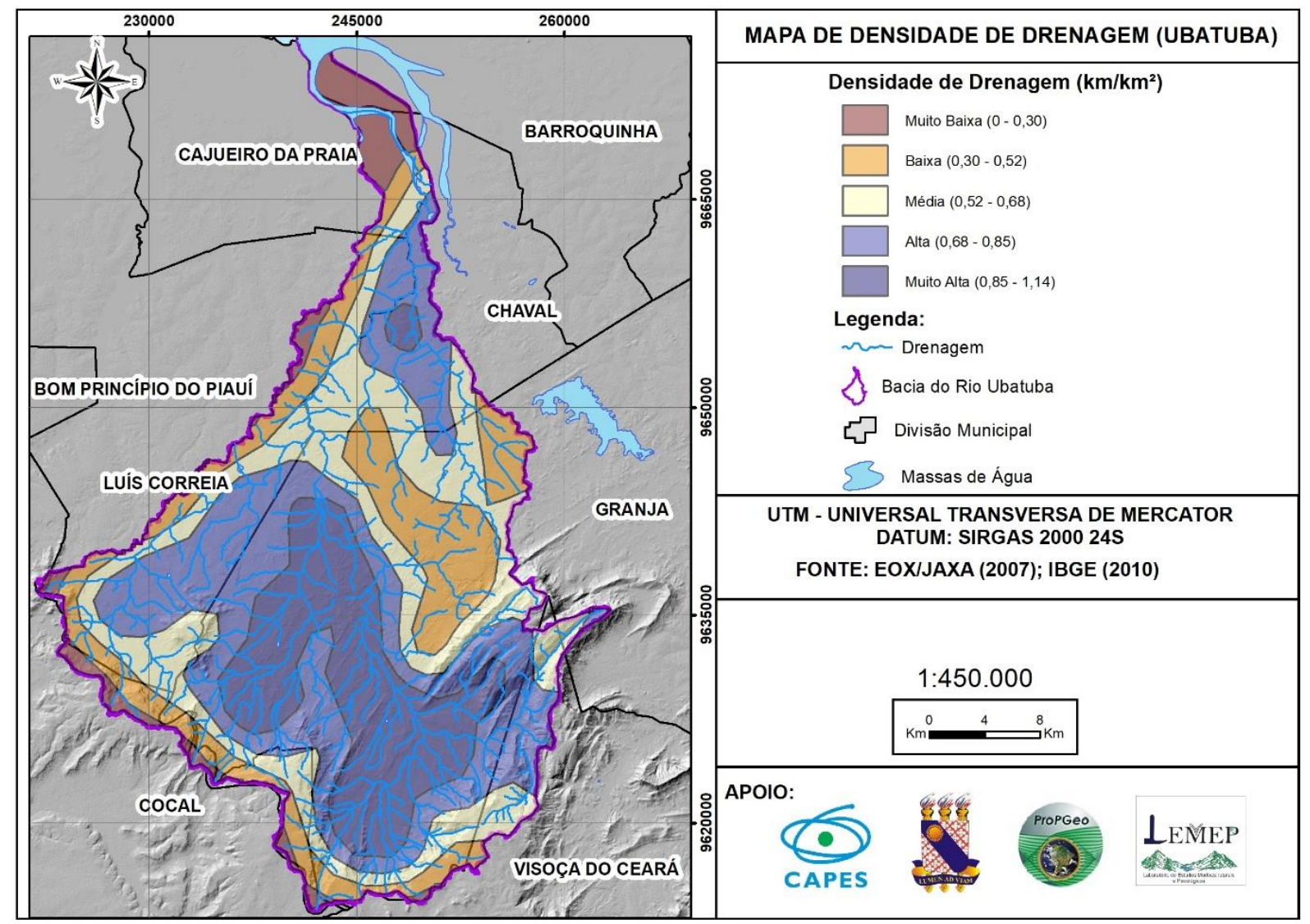

Figura 13. Densidade de Drenagem da Bacia do rio Ubatuba.

A maior densidade de drenagem da bacia do rio Ubatuba coincide com os trends estruturais relacionados com as ZC de Estreito, Granja e Adrianópolis. O escoamento superficial concentrado repercute sobre as ações erosivas nas vertentes por meio do processo de incisão linear e aprofundamento dos vales nas áreas de densidade de drenagem elevada, o que sugere a presença de materiais pouco permeáveis. Quanto maior o gradiente altimétrico nas vertentes, maior será o poder de entalhe das drenagens, principalmente no alto curso, nas drenagens de primeira e segunda ordem. O cenário faz com que a densidade de drenagem seja repercussão da componente lito-estrutural da área.

\subsection{Relação Declividade - Extensão (RDE)}

Para determinação do índice Declividade-Extensão, partiu-se das contribuições desenvolvidas por Hack (1973), com o objetivo de formular o melhor arranjo numérico do perfil longitudinal da drenagem. Empregou-se o cálculo do índice de maneira total e também por trechos de $2 \mathrm{~km}$ ao longo do canal principal. Após esse processo, foram comparados os dois índices como postulado por Barbosa, Lima e Furrier (2013), afim de encontrar setores discrepantes que se enquadrariam como anomalias de perfil.

Os critérios utilizados na comparação do índice RDE-total com o índice RDE-trecho visando se encontrar anomalias tiveram como base a classificação de Seeber e Gornitz (1983) e refinadas por Etchebehere et. al. (2006; 2004). A classificação aponta que valores da divisão RDEtotal/RDEtrecho inferiores a 2 são considerados comuns e sem anomalias; valores iguais ou maiores 2 e menores que $10(2<=x<10)$ são classificados como anomalias de $2^{\mathrm{a}}$ ordem $(\mathrm{x})$, sendo estes são caracterizados por feições íngremes, quebra de ruptura topográfica associado ao fator tectônico e/ou litológico. Os valores acima ou iguais a 10 ( $y>=10)$ são classificados como anomalias de $1^{1}$ a ordem (y), com presença constante do fator tectônico na drenagem refletindo em vertentes extremamente íngremes.

No cálculo do Índice RDE-total para a bacia do rio Ubatuba tem-se um parâmetro equivalente ao valor de 45,60 , que representa um canal moderadamente íngreme. O canal principal foi divido em 38 trechos de $2 \mathrm{~km}$ cada, 
que foram usados para o cálculo do índice RDE-trecho e da relação entre este e o RDE total (Tabela 1). Desse modo, o índice conseguiu expressar 9 trechos com anomalias de $2^{a}$ ordem (2 a 10) e nenhum trecho com anomalia de $1^{a}$ ordem $(>10)$. O que se sugere que são feições íngremes controladas por algum fator estrutural e/ou litológico. As anomalias de $1^{\circ}$ ordem estão ligadas às contribuições mais fiéis da neotectônica, o que neste caso não aparece de forma tão explícita nas drenagens em estudo.

Tabela 1. Amostragem de valores por segmento do índice morfométrico RDE-trecho/RDE total.

\begin{tabular}{|c|c|c|c|c|c|c|c|c|c|}
\hline \multicolumn{10}{|c|}{ Rio Ubatuba - Índice RDE (Relação Declividade Extensão) } \\
\hline Trecho & $\begin{array}{c}\text { Cota } \\
\text { Superior } \\
(\mathrm{m})\end{array}$ & $\begin{array}{l}\text { Cota } \\
\text { Inferior } \\
(\mathrm{m})\end{array}$ & $\begin{array}{l}\text { Diferença } \\
\text { Altimétrica } \\
\text { (m) }\end{array}$ & $\begin{array}{c}\text { Extensão } \\
\text { do Trecho } \\
(\mathrm{km})\end{array}$ & $\begin{array}{l}\text { Extensão } \\
\text { Total (km) }\end{array}$ & $\begin{array}{l}\text { RDE do } \\
\text { Trecho }\end{array}$ & $\begin{array}{l}\text { RDE } \\
\text { Total }\end{array}$ & $\begin{array}{c}\text { RDE do } \\
\text { Trecho/RDE } \\
\text { Total }\end{array}$ & $\begin{array}{l}\text { Ordem da } \\
\text { Anomalia }\end{array}$ \\
\hline 1 & 512 & 348 & 164 & 2 & 2 & 166,07 & 45,6 & 3,641886 & $2^{\mathrm{o}}$ ordem \\
\hline 2 & 348 & 185 & 163 & 2 & 4 & 334,83 & 45,6 & 7,3427632 & $2^{\mathrm{o}}$ ordem \\
\hline 3 & 185 & 128 & 57 & 2 & 6 & 184,8 & 45,6 & 4,0526316 & $2^{\mathrm{o}}$ ordem \\
\hline 4 & 128 & 105 & 23 & 2 & 8 & 100,08 & 45,6 & 2,1947368 & $2^{\circ}$ ordem \\
\hline 5 & 105 & 91 & 14 & 2 & 10 & 90,68 & 45,6 & 1,9885965 & - \\
\hline 6 & 91 & 76 & 15 & 2 & 12 & 113,45 & 45,6 & 2,4879386 & $2^{\mathrm{o}}$ ordem \\
\hline 7 & 76 & 75 & 1 & 2 & 14 & 9,05 & 45,6 & 0,1984649 & - \\
\hline 8 & 75 & 63 & 12 & 2 & 16 & 140,73 & 45,6 & 3,0861842 & $2^{\mathrm{o}}$ ordem \\
\hline 9 & 63 & 56 & 7 & 2 & 18 & 69,62 & 45,6 & 1,5267544 & - \\
\hline 10 & 56 & 55 & 1 & 2 & 20 & 12,7 & 45,6 & 0,2785088 & - \\
\hline 11 & 55 & 47 & 8 & 2 & 22 & 108,18 & 45,6 & 2,3723684 & $2^{\mathrm{o}}$ ordem \\
\hline 12 & 47 & 42 & 5 & 2 & 24 & 65,39 & 45,6 & 1,4339912 & - \\
\hline 13 & 42 & 34 & 8 & 2 & 26 & 119,33 & 45,6 & 2,616886 & $2^{\circ}$ ordem \\
\hline 14 & 34 & 31 & 3 & 2 & 28 & 44,35 & 45,6 & 0,9725877 & - \\
\hline 15 & 31 & 29 & 2 & 2 & 30 & 35,81 & 45,6 & 0,785307 & - \\
\hline 16 & 29 & 28 & 1 & 2 & 32 & 22,95 & 45,6 & 0,5032895 & - \\
\hline 17 & 28 & 24 & 4 & 2 & 34 & 72,05 & 45,6 & 1,5800439 & - \\
\hline 18 & 24 & 21 & 3 & 2 & 36 & 62,92 & 45,6 & 1,3798246 & - \\
\hline 19 & 21 & 18 & 3 & 2 & 38 & 77,88 & 45,6 & 1,7078947 & - \\
\hline 20 & 18 & 16 & 2 & 2 & 40 & 46,63 & 45,6 & 1,0225877 & - \\
\hline 21 & 16 & 15 & 1 & 2 & 42 & 22,22 & 45,6 & 0,4872807 & - \\
\hline 22 & 15 & 11 & 4 & 2 & 44 & 114,74 & 45,6 & 2,5162281 & $2^{\mathrm{o}}$ ordem \\
\hline 23 & 11 & 10 & 1 & 2 & 46 & 24,13 & 45,6 & 0,5291667 & - \\
\hline 24 & 10 & 7 & 3 & 2 & 48 & 86,01 & 45,6 & 1,8861842 & - \\
\hline 25 & 7 & 5 & 2 & 2 & 50 & 64,59 & 45,6 & 1,4164474 & - \\
\hline 26 & 5 & 5 & 0 & 2 & 52 & 0 & 45,6 & 0 & - \\
\hline 27 & 5 & 2 & 3 & 2 & 54 & 85,07 & 45,6 & 1,8655702 & - \\
\hline 28 & 2 & 0 & 2 & 2 & 56 & 57,38 & 45,6 & 1,2583333 & - \\
\hline 29 & 0 & 0 & 0 & 2 & 58 & 0 & 45,6 & 0 & - \\
\hline 30 & 0 & 0 & 0 & 2 & 60 & 0 & 45,6 & 0 & - \\
\hline 31 & 0 & 0 & 0 & 2 & 62 & 0 & 45,6 & 0 & - \\
\hline 32 & 0 & 0 & 0 & 2 & 64 & 0 & 45,6 & 0 & - \\
\hline 33 & 0 & 0 & 0 & 2 & 66 & 0 & 45,6 & 0 & - \\
\hline 34 & 0 & 0 & 0 & 2 & 68 & 0 & 45,6 & 0 & - \\
\hline 35 & 0 & 0 & 0 & 2 & 70 & 0 & 45,6 & 0 & - \\
\hline 36 & 0 & 0 & 0 & 2 & 72 & 0 & 45,6 & 0 & - \\
\hline 37 & 0 & 0 & 0 & 2 & 74 & 0 & 45,6 & 0 & - \\
\hline 38 & 0 & 0 & 0 & 2 & 76 & 0 & 45,6 & 0 & - \\
\hline
\end{tabular}

$\mathrm{Na}$ bacia do rio Ubatuba, as litologias de resistência muito semelhantes na superfície de aplainamento provocaram homogeneização dos valores de RDE-trecho/RDE-total, assim como reflete a manutenção de uma 
declividade moderada a baixa. Esse reflexo minimiza as condicionantes do aspecto estrutural na drenagem dependendo, desse modo, do comportamento da erosão frente às feições geomorfológicas e do tipo de rocha.

Para o comprimento total do canal principal, $21,05 \%$ apresentam anomalias de $2^{\underline{a}}$ ordem, que denotam variação da taxa de altimetria e pontos onde a litologia é mais frágil, facilitando o encaixe fluvial.

O maior valor encontrado para o índice foi de 7,34 na isoieta de $200 \mathrm{~m}$, considerado como o maior ponto de ruptura morfológica ao longo do rio Ubatuba, com diferença altimétrica proporcional a $163 \mathrm{~m}$. Do ponto de vista tectônico, essa anomalia se encontra na área do horst Granja, na discordância da vertente do glint da Ibiapaba e controlado pela aproximação da ZC de Ibuguaçu que segue paralela em alguns segmentos encaixada à drenagem. Desse modo, os pontos de fraqueza gerados pela zona de cisalhamento proporcionaram acomodação da drenagem no mesmo sentido da falha e motivaram erosão em eixo vertical e horizontal. Nesse setor constata-se uma nítida relação entre a Falha de Ibuguaçu e a erosão remontante no setor onde se localiza a nascente do rio Ubatuba.

É possível observar que a maioria das deformações provoca a instalação de zonas de erosão e deposição, acompanhando a evolução dos knickpoints (LANA; CASTRO, 2012). O vale é escavado entre duas estruturas topográficas íngremes, que confinaram o mesmo em um formato retilíneo, oposto ao caimento das camadas sedimentares da borda da bacia sedimentar (Figura 14 - 1).

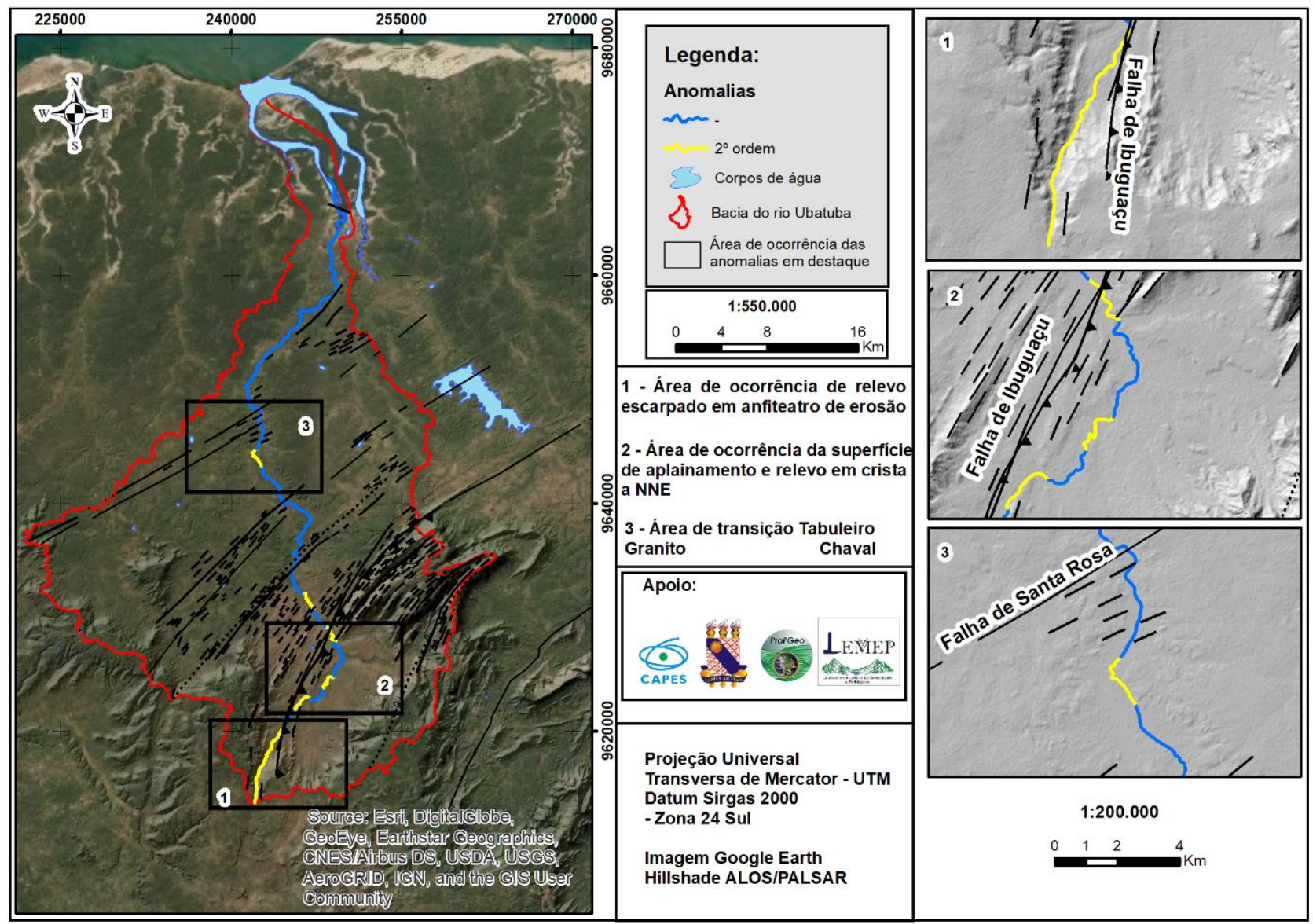

Figura 14. Espacialização do índice RDE (Relação declividade extensão) por trecho de 2 km do canal principal.

A Figura $14-2$ apresenta drenagem com pontos de inflexão em ângulo agudo, cujas anomalias estão associadas a uma zona de cisalhamento (ZC de Ibuguaçu), e a drenagem aqui situa-se em um anfiteatro erosivo já nas cotas de superfície de aplainamento $( \pm 150 \mathrm{~m})$, com alguns sedimentos coluvio-eluviais e rochas da Fm Covão.

Os knickpoints, neste caso, não estão associados somente ao contraste topográfico, mas a variações do nível de base regional que seria a próprio vale do rio Ubatuba e do anfiteatro erosivo anteriormente mencionado. Esse tipo de ruptura possui estreita relação com propriedades estruturais locais, como a atitude e espessura dos estratos dissecados, frequência e orientação dos lineamentos (LANA; CASTRO, 2012). 
A Figura 14 - 3 refere-se a uma importante inflexão em ângulo agudo que faz com que a drenagem tenha uma tendência para $\mathrm{E}$, com diferença de altitude de $4 \mathrm{~m}$ sem relevos expressivos que se mostrem como altos topográficos. Percebe-se que os processos de deposição do canal principal já são maiores, pois nesse setor o mesmo já não tem gradiente necessário para escarvar o terreno. Nesse setor ocorre a exumação do granito Chaval, na qual a drenagem se encontra confinada. A direção da anomalia condiz com a proximidade da Falha de Santa Rosa e com a orientação dos planos de falha deixada por reativação ao longo da Fm Goiabeira e da Suíte Granítica Chaval (ABREU et al., 1988).

Com a criação do perfil longitudinal logarítmico e de altitude (Figuras 15 e 16), foram identificados 13 pontos dispersos fora da curva de tendência dos valores em vermelho, todos eles acima de 60 . A amostra aponta que os índices RDE-trecho estão, desse modo, acima da realidade do rio Ubatuba que supera o valor do RDE-total, registrando relevo bastante dissecado nos pontos descritos.

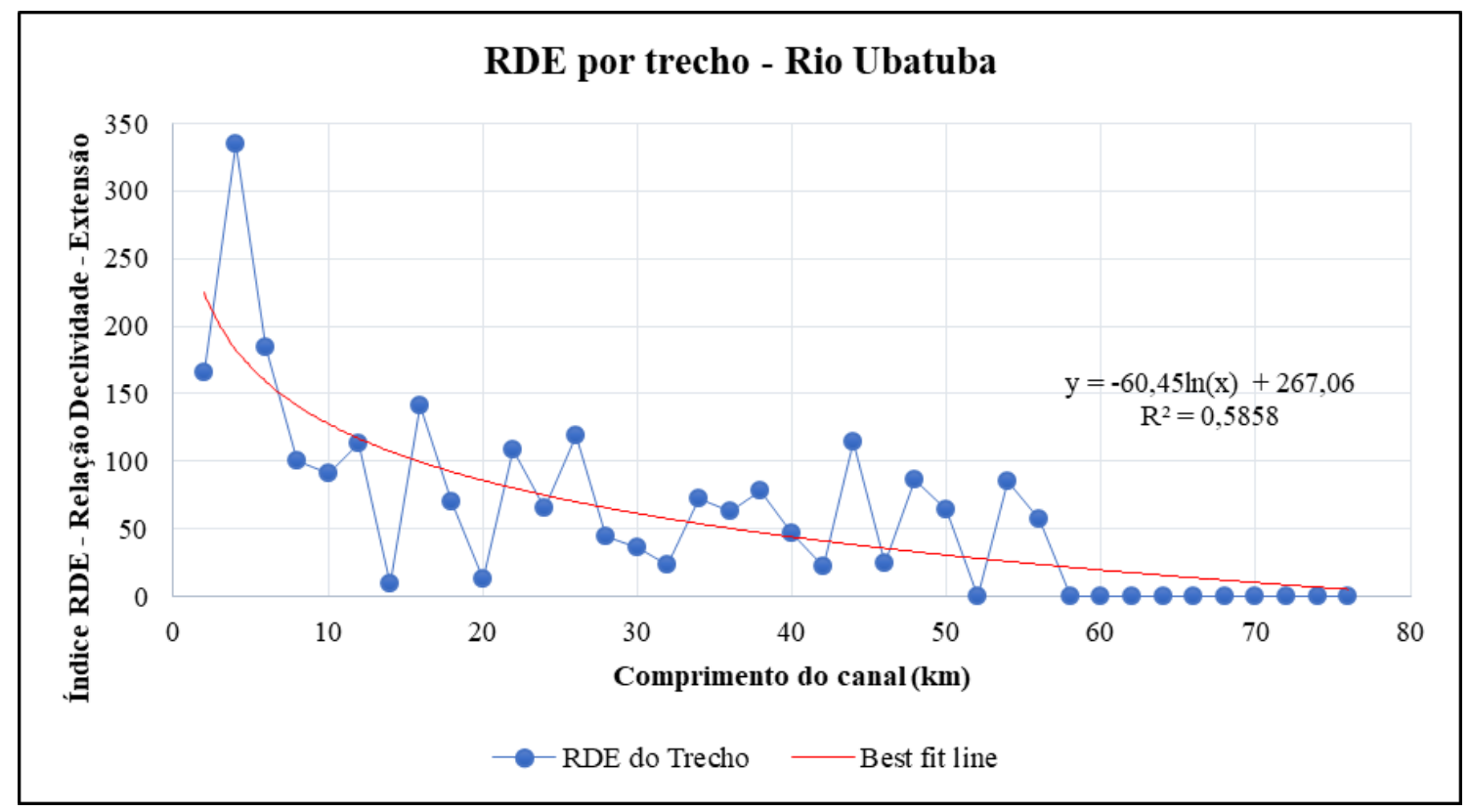

Figura 15. Normalização dos valores do índice RDE ao longo do canal do rio Ubatuba.

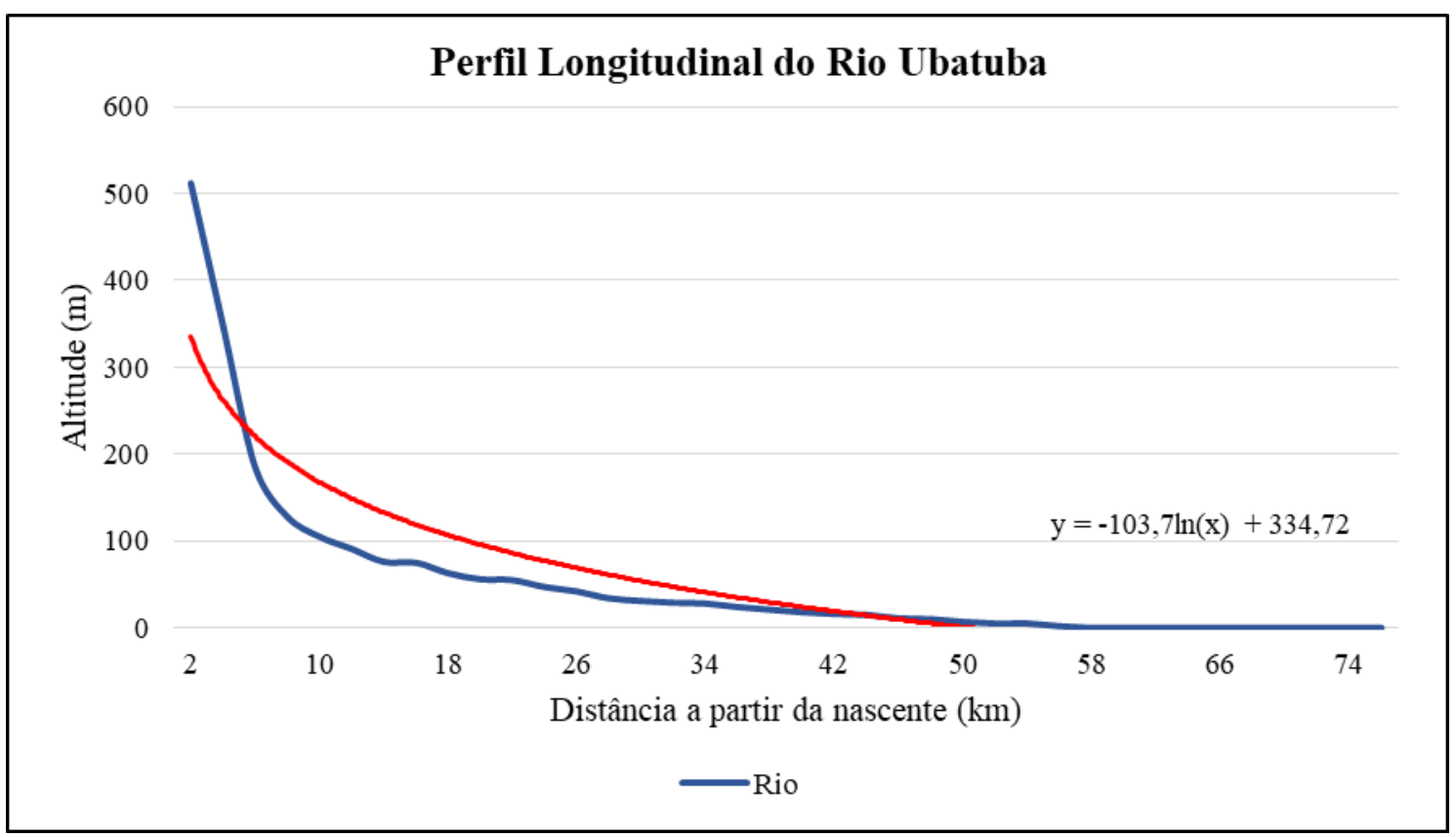

Figura 16. Perfil Longitudinal do rio Ubatuba. 
No trecho localizado entre altitudes de 76 a $63 \mathrm{~m}$ ocorre um segmento côncavo de extensão de $4 \mathrm{~km}$, representando o ambiente em que a drenagem escavou com mais facilidade. Ao se analisar a linha de maior tendência foi possível identificar a ocorrência de setores em equilíbrio e anomalias.

As anomalias são verificadas pelo afastamento da drenagem da linha de tendência, em vermelho, que foram classificadas como anomalias positivas e negativas. Ressalta-se que as anomalias positivas constituem processos de ascensão e as negativas processos de subsidência do substrato do canal. A partir dessa realidade, verificou-se no alto curso um trecho de até $34 \mathrm{~km}$ com processo de subsidência e, por consequência, anomalia negativa. O formato do perfil na nascente se trata de um recuo do relevo, com direção à vertente do glint Ibiapaba e erosão remontante em curso.

Com a setorização do índice RDE-total para drenagens acima de $10 \mathrm{~km}$, verificou-se que a concentração dos maiores valores do RDE está localizada no setor SE da bacia (Tabela 2). Esta porção é caracterizada por litologias cristalinas, sobretudo quartzitos da Fm São Joaquim, com canais retilíneos como o caso do riacho Cantagalo. número (por exemplo, Tabela 1).

Tabela 2. Valores do Índice RDE total dos rios acima de $10 \mathrm{~km}$ da bacia do rio Ubatuba.

\begin{tabular}{cccccc}
\hline \multicolumn{7}{c}{ Índice RDE por canal acima de 10km } \\
\hline Toponímia & $\begin{array}{c}\text { Cota } \\
\text { Superior }(\mathbf{m})\end{array}$ & $\begin{array}{c}\text { Cota } \\
\text { Inferior }(\mathbf{m})\end{array}$ & $\begin{array}{c}\text { Diferença } \\
\text { Altimétrica }(\mathbf{m})\end{array}$ & $\begin{array}{c}\text { Extensão do } \\
\text { Canal }(\mathbf{m})\end{array}$ & $\begin{array}{c}\text { RDE } \\
\text { total }\end{array}$ \\
\hline Rio Ubatuba & 512 & 0 & 512 & 76010 & 45,6 \\
Riacho Boqueirão & 656 & 58 & 598 & 19833,9 & 60,5 \\
Riacho Cantagalo & 851 & 55 & 796 & 11682,83 & 85,08 \\
Grota do Olho d'Aguinha & 254 & 35 & 219 & 10574 & 23,66 \\
Riacho Cajueiro & 98 & 0 & 98 & 26436,58 & 9,63 \\
Riacho Carnaúba & 305 & 13 & 292 & 22406,6 & 29,18 \\
Riacho Santa Rosa & 154 & 7 & 147 & 33346,95 & 14,13 \\
Riacho do Pinto & 103 & 33 & 70 & 10305,57 & 7,6 \\
Riacho dos Poções & 347 & 24 & 323 & 15837,75 & 33,44 \\
Riacho Pirapora & 823 & 47 & 776 & 14431,8 & 81,11 \\
\hline
\end{tabular}

Em decorrência da associação espacial do processo de erosão atribui-se ao índice RDE-total afinidade com o padrão de drenagem treliça na bacia do rio Ubatuba. O riacho Cantagalo possui corredeiras acentuadas com diferença altimétrica de $796 \mathrm{~m}$ e alta rugosidade, representando o maior valor dentre as drenagens analisadas, associado a lineamento negativo de sentido NE. O riacho Boqueirão também apresenta valores elevados do índice RDE-total e do padrão principal nas cristas, com diferença altimétrica de $598 \mathrm{~m}$. As drenagens situadas à direita do rio principal tiveram condições favoráveis ao encaixe no sentido NE, próximo à zona de cisalhamento de Santa Rosa e Estreito.

A baixa concentração do RDE-total coincide com a área de transição entre o tabuleiro e a superfície de aplainamento, onde o relevo tem baixa declividade e sem expressividade do fator estrutural (Figura 17). Em decorrência da homogeneidade litológica associada a rochas paraderivadas tenras, a ação erosiva gerou uma superfície suavemente ondulada, com cotas médias de $200 \mathrm{~m}$, drenada por rios insequentes em que o índice não refletiu mudanças significativas na drenagem. Nesse sentido, os menores valores do índice RDE-total compreendem os setores onde estão presentes os riachos Cajueiro e Riacho do Pinto. 


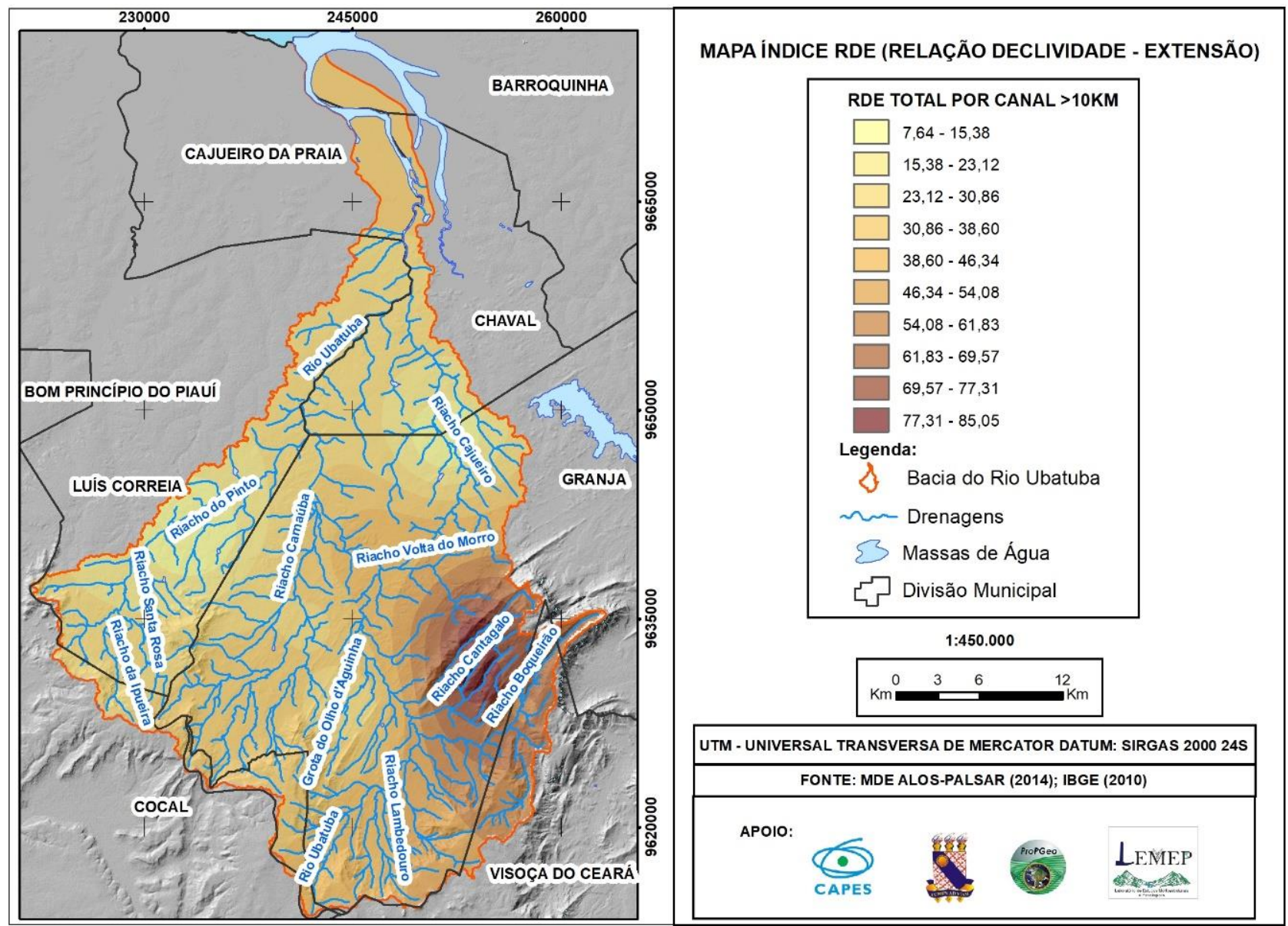

Figura 17. Espacialização do índice RDE total.

Em contrapartida, o riacho do Pinto está próximo à zona de cisalhamento, que delimita o granito Chaval e as rochas da Fm Goiabeira. Este fator não alterou os valores do RDE-trecho/RDE-total na extensão do riacho, porém condicionou a sua direção. Essa característica se processa através da condicionante da ZC de Santa Rosa que ocorre paralelamente e encaixada com a drenagem desse riacho.

\section{Conclusões}

A utilização do índice RDE no rio Ubatuba possibilitou a realização de discussões instigantes ao se relacionar anomalias com os aspectos estruturais. De maneira geral, tais anomalias coincidiram com transições abruptas de contextos litológicos distintos em termos de resistência e também com deformações tectônicas associadas a falhas e zonas de cisalhamento. Cabe ressaltar que tais deformações não configuram, necessariamente, eventos neotectônicos e provavelmente se devem à diversidade litológica que justifica uma expressiva variação topográfica ao longo da bacia.

Cabe destacar que mesmo sem grandes evidências de influência tectônica nas anomalias identificadas pelo índice RDE, a aplicação desse índice permitiu, através de procedimentos simples e rápidos, a identificação de áreas/setores de interesse morfoestrutural/morfotectônico para interpretações posteriores de maior detalhe, confirmando, dessa forma, a importância da aplicação desse método.

Mesmo com as constatações apresentadas, não podem ser descartadas as possibilidades de influência neotectônica em outros tipos de fenômenos fluviais do canal principal, tais como terraceamentos e deslocamentos de leitos. No entanto, para se confirmar tais processos, fazem-se necessários estudos posteriores com o levantamento de amostras e análises sedimentológica detalhadas, além do uso de métodos geocronológicos.

O fator topográfico foi levado em consideração, assim como os dados litoestruturais complementaram a interpretação dos resultados levantados com o índice RDE. Este parâmetro serviu de ensaio para identificar os diferentes comportamentos dos canais e contribuir, desta forma, com a interpretação acerca da evolução geomorfológica da bacia do rio Ubatuba. Além do índice RDE, a presente análise também considerou outros 
índices morfométricos que permitiram compreender diversos parâmetros associados à uma análise morfoestrutural satisfatória.

Constata-se que o controle estrutural da rede de drenagem é evidente de maneira que existem estreitas relações entre os aspectos estruturais e a organização dos canais. Isso pode ser observado no nítido condicionamento das deformações de direção NE com o sentido preferencial dos canais de $2^{\underline{a}}$ e $3^{\underline{a}}$ ordem nesse mesmo sentido. Além disso, constata-se uma clara relação espacial entre a densidade de lineamentos e a densidade de drenagem com setores de maior densidade situados no alto curso da bacia. Por fim, constata-se uma nítida relação entre a composição litoestrutural com os padrões de drenagem identificados ao longo da bacia, com padrões treliça, nas áreas de quartzitos, e paralelos, no contato entre o arenito e o embasamento, ambos no alto curso, padrões dendríticos associados com rochas paraderivadas no médio curso e padrão anastomosado sobre os depósitos quaternários no baixo curso.

Contribuições dos Autores: O autor principal, Yuri da Silva Belarmino, foi responsável pela concepção inicial do artigo tendo levantado os dados através de consultas bibliográficas, uso de técnicas de geoprocessamento e trabalhos de campo, assim como foi o responsável pelos resultados alcançados. Já o segundo autor, Frederico de Holanda Bastos, participou dos levantamentos de campo e foi responsável por estruturar o artigo, fazer as discussões e revisões.

Financiamento: Esta pesquisa foi financiada pela Coordenação de Aperfeiçoamento de Pessoal de Nível Superior (CAPES)

Agradecimentos: Os autores agradecem à Coordenação de Aperfeiçoamento de Pessoal de Nível Superior (CAPES) pela bolsa de fomento de nível de mestrado, concedida através do Programa de Pós-Graduação em Geografia (ProPGeo) da Universidade Estadual do Ceará (UECE), e ao Laboratório de Estudos Morfoestruturais e Pedológicos pela disponibilidade de acervo científico e bibliográfico.

Conflito de Interesse: Os autores declaram não haver conflito de interesse.

\section{Referências}

1. ABREU, F. A. M.; GAMA JUNIOR, T.; GORAYEB, P. S. S.; HASUI, Y. O Cinturão de Cisalhamento Noroeste do Ceará. In: Congresso Latino-Americano de Geologia, 7., 1988, Belém, PA. Anais... Belém: Sociedade Brasileira de Geologia. 1988. p. 20-34.

2. ALMEIDA F. F. M.; HASUI, Y.; BRITO NEVES B. B.; FUCK R. A. Províncias estruturais brasileiras. In: Simpósio de Geologia do Nordeste, 8., 1977, Campina Grande, PB. Anais... Campina Grande: Atas. 1997. p. 363-391.

3. ANDRADES FILHO, C. O. Análise morfoestrutural da porção central da Bacia Paraíba (PB) a partir de dados MDE-SRTM e ALOS-PALSAR FBD. Dissertação (Mestrado em Sensoriamento Remoto). Instituto Nacional de Pesquisas Espaciais, Ribeirão Preto. 2010. 177 p.

4. ANDRADES FILHO, C. O.; ROSSETTI, D. F. Effectiveness of SRTM and ALOSPALSAR data for identifying morphostructural lineaments in northeastern Brazil. International Journal of Remote Sensing, v. 33, n. 4, 2012.

5. ANGELIM, L. A. A.; VASCONCELOS, A. M.; GOMES, I. P.; SANTOS, E. J. Geotectônica do Escudo Atlântico: Província Borborema. In: BIZZI, L. A.; SCHOBBENHAUS, C.; VIDOTTI, R. M.; GONÇALVES, J. H. (Org.). Geologia, tectônica e recursos minerais do Brasil: textos, mapas \& SIG. $1^{a}$ Ed. Brasília: CPRM, 2003. p. 264-281.

6. BAHRAMI, S. Analyzing the drainage system anomaly of Zagros basins: Implications for active tectonics. Tectonophysics, v. 608, p. 914-928, 2013. DOI: 10.1016/j.tecto.2013.07.026

7. BARBOSA, T. S.; LIMA, V. F.; FURRIER, M. Anomalias em padrões de redes de drenagem como fator de verificação de neotectônica - um estudo de caso nas sub-bacias do rio Mamuaba-PB. Revista do Departamento de Geografia da USP, v. 26, p. 193-213, 2013. DOI: 10.7154/RDG.2013.0026.0010

8. BEG. A. A. F. Morphometric Toolbox: A New Technique in Basin Morphometric Analysis Using ArcGIS. Global Journal of Earth Science and Engineering. v. 2, 2015. DOI: 10.15377/2409-5710.2015.02.02.1

9. BIGARELLA, J. J.; MOUSINHO, M. R.; SILVA, J. X. Pediplanos, pedimentos e seus depósitos correlativos no Brasil. Espaço Aberto, v. 6, n. 2, p. 165-196, 2016. DOI: 10.36403/espacoaberto.2016.7650

10. BISHOP, P. Drainage rearrangement by river capture, beheading and diversion. Progress in physical geography, v. 19, $n$. 4, p. 449-473, 1995.

11. BRICALLI, L. L. Procedimentos Metodológicos e Técnicas em Geomorfologia Tectônica. Espaço Aberto, v. 6, n. 1, p. 75-110, 2016. DOI: 10.36403/espacoaberto.2016.5239

12. BRITO NEVES, B. B. Regionalização geotectônica do Pré-cambriano nordestino. Tese (Doutorado em Geologia Sedimentar) - Instituto de Geociências, Universidade de São Paulo, São Paulo. 1975. 207 p. 
13. CACAMA, M. S. J. B. Assinatura Estrutural e Geofísica da Porção Norte (Fronteira Ceará-Piauí) do Lineamento Transbrasiliano: Reativação na Bacia do Parnaíba. Dissertação (Dissertação em Geodinâmica e Geofísica) - Centro de Ciências Exatas e da Terra, Universidade Federal do Rio Grande do Norte. Natal. 2015. 92 p.

14. CAVAlCANTE, J. C.; VASCONCELOS, A. M.; MEDEIROS, M. F.; PAIVA, I. P.; GOMES, F. E. M.; CAVALCANTE, S. N.; CAVALCANTE, J. E.; MELO, A. C. R.; DUARTE NETO, V. C.; BENEVIDES, H. C. Mapa geológico do estado do Ceará Fortaleza: CPRM, 2003. Escala 1:500.000.

15. CHRISTOFOLETTI, A. Geomorfologia. 1ª Ed. São Paulo: Edgard Blucher, 2 ed. 1980. 188p.

16. CLAUDINO-SALES, V.; LIRA, M. C. Megageomorfologia do Noroeste do estado do Ceará, Brasil. Revista Caminhos de Geografia-UFU, Uberlândia-MG, v. 12, n 38, p. 200-209, 2011.

17. COSTA, M. J.; FRANÇA, J. B.; LINS, C. A. C.; BACCHIEGGA, I. F.; HABEKOST, C. R.; CRUZ, W. B. Geologia da Bacia Jaibaras: Ceará Piauí e Maranhão. Projeto Jaibaras. Ministério das Minas e Energia (MME) / Departamento Nacional da Produção Mineral. Brasília: (DNPM), 1979.

18. DINGMAN, S. L. Drainage density and streamflow: A closer look. Water Resources Research, v. 14, n. 6, p. 1183-1187, 1978. DOI: 10.1029/WR014i006p01183

19. ETCHEBEHERE, M. L. C.; SAAD, A. R.; FULFARO, V. J. PERINOTTO, J. A. J. Aplicação do índice “Relação Declividade Extensão" na bacia do Rio do Peixe (SP) para detecção de deformações neotectônicas. Geologia USP. Série científica, v. 4, n. 2, 43 - 56. 2004.

20. ETCHEBEHERE, M. L. C.; SAAD, A. R.; SANTONI, G. C.; CASADO, F. C.; FULFARO, V. J. Detecção de prováveis deformações neotectônicas no vale do Rio do Peixe, região ocidental paulista mediante aplicação de índices RDE (Relação Declividade-Extensão) em segmentos de drenagem. Revista de Geociências USP, v. 25, n. 3, p. 271-289. 2006.

21. HACK, J. T. Stream-profile analysis and stream-gradient index. Journal of Research of the United States Geological Survey, v. 1, n. 4, p. 421-429, 1973.

22. HORTON, R. E. Erosional development of streams and their drainage basins; hydrophysical approach to quantitative morphology. Geological Society of America Bulletin, v. 56, n. 3, p. 275- 370, 1945.

23. HOWARD, A. D. Drainage analysis in geologic interpretation: a summation. AAPG bulletin, v. 51, n. 11, p. 2246-2259, 1967.

24. IBGE. Manual Técnico de Geomorfologia. 2. ed. Rio de Janeiro: Instituto Brasileiro de Geografia e Estatística, 2009. n. 5. $182 \mathrm{p}$.

25. LANA, C. E.; CASTRO, P. T. A. Níveis de base fluviais: síntese dos principais condicionantes e dinâmica de instalação. Brazilian Geographical Journal, Uberlândia, v. 3, n. 1, p. 102-122, 2012.

26. LIMA, M. G. A história do intemperismo na Província Borborema Oriental, Nordeste do Brasil: implicações paleoclimáticas e tectônicas. Tese (Doutorado em Geodinâmica; Geofísica) - Programa de Pós-Graduação em Geodinâmica e Geofísica, Universidade Federal do Rio Grande do Norte, Natal. 2008. 594 p.

27. CHIANG, L. C. Análise estrutural de lineamentos em imagens de sensoriamento remoto: aplicação ao Estado do Rio de Janeiro. Tese (Doutorado em Geociências) - Instituto de Geociências, Universidade de São Paulo, São Paulo. 1984.183 p.

28. LUO, W.; HOWARD, A. D. Morphometric analysis of Martian valley network basins using a circularity function. Journal of Geophysical Research, v. 110, n. E12, 2005. DOI: 10.1029/2005JE002506

29. MAIA, R. P.; BEZERRA, F. H. R.; CLAUDINO-SALES, V. Geomorfologia do Nordeste: concepções clássicas e atuais acerca das superfícies de aplainamento nordestinas. Revista de Geografia, v. especial SINAGEO 8, n. 1, p. 6-19, 2010.

30. MAIA, R. P.; BEZERRA, F. H. R. Neotectônica, geomorfologia e sistemas fluviais: uma análise preliminar do contexto nordestino. Revista Brasileira de Geomorfologia, v. 12, n. 3, p. 37-46, 2011. DOI: 10.20502/rbg.v12i0.257

31. MOURA-FÉ, M. M. Evolução morfoestrutural Cretácea da Ibiapaba setentrional, região Noroeste do estado do Ceará Geo UERJ, n. 31, p. 389-416, 2017. DOI: 10.12957/geouerj.2017.28327

32. NOGUEIRA NETO, J. A.; MAGINI, C.; SANTOS, T. J. S.; PRAXEDES, I. F.; CARNEIRO, A. A. Granja, folha SA.24-Y-C-III, escala 1:100.000. Estado do Ceará. Brasília: CPRM, 2014.

33. O'LEARY, D. W.; FRIEDMAN, J. D.; POHN, H. A. Lineament, linear, lineation: Some proposed new standards for old terms: Discussion and reply. Geological Society of America Bulletin, v. 89, n. 1, p. 159-160, 1978. DOI: 10.1130/0016-7606(1978)89<159b:LLLSPN>2.0.CO;2

34. PARETA, K.; PARETA, U. Quantitative morphometric analysis of a watershed of Yamuna basin, India using ASTER (DEM) data and GIS. International journal of Geomatics and Geosciences, v. 2, n. 1, p. 248-269, 2011.

35. PEULVAST, J. P.; CLAUDINO-SALES, V. Reconstruindo a evolução de uma margem continental passiva: um estudo morfogenético do Nordeste brasileiro. In: SILVA, J. B.; LIMA, L. C.; ELIAS, D. S. (Org.). Panorama da Geografia Brasileira. 1ª Ed. São Paulo: Annablume, 2006. 
36. PINÉO, T. R. G.; LIMA, A. F.; BESSA, M. D. M. R.; MARTINS M. D. Chaval, folha - SA.24-Y-C-II, escala 1:100.000. Estado do Ceará. Fortaleza: CPRM, 2018.

37. RADAIDEH, O. M. A.; MOSAR, J. Tectonics controls on fluvial landscapes and drainage development in the westernmost part of Switzerland: Insights from DEM-derived geomorphic indices. Tectonophysics, v. 768, p. 1-29, 2019. DOI:10.1016/j.tecto.2019.228179

38. RUBIN, J. C. R. Sedimentação quaternária, contexto paleoambiental e interação antrópica nos depósitos aluviais do Alto rio Meia Ponte - Goiás/GO. Tese (Doutorado em Geociências) - Instituto de Geociências e Ciências Exatas, Universidade Estadual Paulista, Rio Claro. 2002. 354p.

39. SAADI, A.; TORQUATO, J. R. Contribuição á neotectônica do estado do Ceará. Revista de Geologia, Fortaleza, v. 5, p. $5-38,1992$.

40. SANTOS, E. J.; BRITO NEVES, B. B. A Província Borborema. In: ALMEIDA, F. M.; HASSUI, Y. O Pré-Cambriano do Brasil. São Paulo: Edgard Blucher, 1984.

41. SANTOS, T. J. S.; FETTER, A. H.; HACKSPACHER, P. C.; SCHMUS, W. R. V.; NOGUEIRA NETO, J. A. Neoproterozoic tectonic and magmatic episodes in the NW sector of Borborema Province, NE Brazil, during assembly of Western Gondwana. Journal of South American Earth Sciences, v. 25, n. 3, p. 271-284, 2008. DOI: 10.1016/j.jsames.2007.05.006

42. SCHUMM, S. A. River response to baselevel change: implications for sequence stratigraphy. The Journal of Geology, v. 101, n. 2, p. 279-294, 1993.

43. SEEBER, L.; GORNITZ, V. River profiles along the Himalayan arc as indicators of active tectonics. Tectonophysics, v. 92, n. 4 , p. 335-367, 1983

44. SEMA. Parque Estadual das Carnaúbas. Secretaria do Meio Ambiente. Fortaleza, 31 maio 2013. Disponível em: <https://www.sema.ce.gov.br/2013/05/31/parque-estadual-das-carnaubas/>. Acesso em: 25 set. 2019.

45. SILVA, A. J. P.; LOPES, R. C.; VASCONCELOS, A. M.; BAHIA, R. B. C. Bacias Sedimentares Paleozóicas e Meso-Cenozóicas Interiores. In: BIZZI, L. A.; SCHOBBENHAUS, C.; VIDOTTI, R. M.; GONÇALVES, J. H. Geologia, Tectônica e Recursos Minerais do Brasil. 1aํ Ed. Brasília: CPRM, 2003. p. 55-85. Disponível em: $<$ http://www.cprm.gov.br/publique/media/recursos_minerais/livro_geo_tec_rm/capII.pdf>. Acesso em: 25 jun. 2019.

46. SOUZA, M. J. N. Contribuição ao Estudo das Unidades Morfo-Estruturais do Ceará. Revista de Geologia (Fortaleza), Fortaleza, v. 1, 1988.

47. STRAHLER, A. N. Hypsometric (area-altitude) analysis of erosional topography. Geological Society of America Bulletin, v. 63, n. 11, p. 1117-1142, 1952.

48. TORQUATO, J. R.; NOGUEIRA NETO, J. A. Historiografia da Região de Dobramentos do Médio Coreaú. Revista Brasileira de Geociências, v. 26, n. 4, p. 303-314, 1996.

49. VAUCHEZ, A.; NEVES, S.; CABY, R.; CORSINI, M.; EGYDIO SILVA, M.; The Borborema shear zone system, NE Brazil. Journal of South American Earth Sciences, v. 8, n. 3-4, p. 247-266, 1995.

50. ZHANG, L.; GUILBERT, E. Automatic Drainage Pattern Recognition in River Networks. International Journal of Geographical Information Science, v. 27, n. 12, p. 2319-2342, 2013. DOI: 10.1080/13658816.2013.802794

Esta obra está licenciada com uma Licença Creative Commons Atribuição 4.0 Internacional (http://creativecommons.org/licenses/by/4.0/) - CC BY. Esta licença permite que outros distribuam, remixem, adaptem e criem a partir do seu trabalho, mesmo para fins comerciais, desde que lhe atribuam o devido crédito pela criação original. 